The author(s) shown below used Federal funds provided by the U.S. Department of Justice and prepared the following final report:

Document Title: Spreading the Wealth: The Effect of the Distribution of Income and Race/Ethnicity across Households and Neighborhoods on City Crime Trajectories

Author: John R. Hipp

Document No.: 232084

Date Received: October 2010

Award Number: $\quad$ 2008-IJ-CX-0020

This report has not been published by the U.S. Department of Justice. To provide better customer service, NCJRS has made this Federallyfunded grant final report available electronically in addition to traditional paper copies.

Opinions or points of view expressed are those of the author(s) and do not necessarily reflect the official position or policies of the U.S. Department of Justice. 
Spreading the wealth: The effect of the distribution of income and race/ethnicity across households and neighborhoods on city crime trajectories

Final Report

John R. Hipp*

May 27, 2010

NIJ Grant Number: 2008-IJ-CX-0020

* Department of Criminology, Law and Society and Department of Sociology, University of California, Irvine. Address correspondence to John R. Hipp, Department of Criminology, Law and Society, University of California, Irvine, 2367 Social Ecology II, Irvine, CA 92697; email: john.hipp@UCI.edu. Thanks to Daniel K. Yates, who helped in early portions of the analyses. 


\title{
Spreading the wealth: The effect of the distribution of income and race/ethnicity across households and neighborhoods on city crime trajectories
}

\author{
Abstract \\ This study focuses on the effect of economic resources and racial/ethnic \\ composition on the change in crime rates over a 30-year period in 352 cities in \\ metropolitan areas that experienced a large growth in population after World War II. The \\ key findings are that whereas inequality increases the amount of crime in cities, the \\ distribution of this inequality across the census tracts of the city has important interaction \\ effects. Thus, in cities with high levels of inequality, higher levels of economic \\ segregation actually lead to much higher levels of the types of crime studied here \\ (aggravated assaults, robberies, burglaries, and motor vehicle thefts). In contrast, in cities \\ with low levels of inequality, it is mixing of households in neighborhoods with varying \\ levels of income that leads to higher levels of crime. Likewise, we found an important \\ interaction between the racial/ethnic composition of the city and how these groups are \\ distributed across the neighborhoods of the city. In cities with high levels of racial/ethnic \\ heterogeneity, higher levels of segregation of these groups leads to particularly high \\ overall levels of crime in these cities. In cities with low levels of racial/ethnic \\ heterogeneity, greater mixing of groups in neighborhoods actually increases the crime \\ rate. These are important, novel findings.
}




\section{Spreading the wealth: The effect of the distribution of income and race/ethnicity across households and neighborhoods on city crime trajectories}

Regardless of the ecological unit of analysis under study, research attempting to explain the level of crime nearly always focuses on the role of two key constructs: the economic resources and the racial/ethnic composition of the geographic unit. This research focuses on the composition of economic resources and race/ethnicity in a geographic unit, as well as how they are distributed within the unit. Whether focusing on neighborhoods, cities, counties, or even larger aggregations, studies often posit and test whether the composition and distribution of these constructs are related to higher levels of property and violent crime. Thus, numerous studies have tested whether the presence of more racial/ethnic minorities is related to higher levels of crime, across various geographic aggregations such as neighborhoods (Crutchfield 1989; Hannon and Knapp 2003; Krivo and Peterson 1996; Ouimet 2000; Peterson, Krivo, and Harris 2000; Roncek 1981). Some studies have found a positive effect for the presence of racial/ethnic minorities even when accounting for the level of racial/ethnic heterogeneity (Hipp 2007; Roncek and Maier 1991) or larger units such as cities or metropolitan areas (Beyerlein and Hipp 2005; Chamlin and Cochran 1997; Kawachi, Kennedy, Lochner, and Prothrow-Stith 1997; Kovandzic, Vieratis, and Yeisley 1998; Land, McCall, and Cohen 1990; Liska and Bellair 1995; Messner 1983b; Miethe, Hughes, and McDowall 1991; Ousey 1999; Sampson 1985; Wilkinson 1996). Likewise, studies have frequently asked whether the distribution of race/ethnicity—-the racial/ethnic heterogeneity in an area_leads to higher rates of crime in counties (McVeigh 2006), and cities (Hipp, Bauer, Curran, and Bollen 2004). There is also an abundance of studies testing whether low levels of economic resources as measured by concentrated disadvantage are associated with more crime in neighborhoods (Crutchfield 1989; Hipp 2007; Krivo and Peterson 
1996; McClain 1989; Messner and Tardiff 1986; Warner and Pierce 1993; Warner and Rountree 1997) or larger units of analysis (Bainbridge 1989; Beyerlein and Hipp 2005; Chamlin and Cochran 1997; Crutchfield, Geerken, and Gove 1982; Gibbs and Erickson 1976; Harer and Steffensmeier 1992; Hipp, Bauer, Curran, and Bollen 2004; Liska and Bellair 1995; Liska, Logan, and Bellair 1998; Messner and Blau 1987; Shihadeh and Ousey 1996). And other research has focused on whether the distribution of income — higher levels of inequality—leads to more crime in neighborhoods (Crutchfield 1989; Hipp 2007) or larger units (Blau and Blau 1982; Chamlin and Cochran 1997; Golden and Messner 1987; Harer and Steffensmeier 1992; Kposowa, Breault, and Harrison 1995; Land, McCall, and Cohen 1990; Ousey 1999; Simpson 1985).

Early research considered the level and distribution of race/ethnicity and economic resources at the geographic-level of the city. This research tested whether cities with higher levels of income or a more equitable distribution of income (equality) would experience lower rates of crime (Blau and Blau 1982; Chamlin and Cochran 1997; Golden and Messner 1987; Harer and Steffensmeier 1992; Kposowa, Breault, and Harrison 1995; Land, McCall, and Cohen 1990; Ousey 1999; Simpson 1985). Likewise, research tested whether cities with higher levels of non-white residents or a greater mixing of racial/ethnic groups (heterogeneity) would experience higher rates of crime (Hipp, Bauer, Curran, and Bollen 2004; McVeigh 2006). If indeed the mechanisms through which inequality and racial/ethnic composition work operate at such a macro level, these approaches are fine. However, some have argued that the mechanisms operate at the more proximal level of neighborhoods. Thus, more recent research has used neighborhoods as the unit of analysis to test whether these same constructs impact neighborhood-level crime (Bellair 1997; Hipp 2007; Sampson and Groves 1989; Shaw and McKay 1942; Veysey and Messner 1999; Warner and Pierce 1993; Warner and Rountree 1997). 
This raises an important question regarding the geographic unit of analysis at which these mechanisms operate: if they indeed operate at the scale of the city, then we should not necessarily expect to observe such effects at the neighborhood level. However, if these mechanisms actually operate at the neighborhood-level, then how these constructs are distributed geographically throughout the city may have important implications for crime rates. At root, the question is whether these constructs indeed exhibit a degree of scale invariance. With the exception of a recent cross-sectional study viewing homicide rates of African-Americans in central cities (Lee and Ousey 2007), studies have generally failed to test this proposition.

Furthermore, even less consideration has been given to the possible effect that changes in this residential segregation by income and race may have for the crime trajectories of cities. We do so here by incorporating both cross-sectional and longitudinal analyses. The cross-sectional models capture the long-run equilibrium in these processes, whereas our longitudinal models capture the effect of the change in various city characteristics on the change in crime rates.

By viewing the trajectories of crime rates of cities in fourteen similar areas (areas that have seen dramatic population growth since World War II) we intend to tease out these effects. We begin by describing the theoretical perspectives positing the importance of race and class for crime rates across neighborhoods and cities, and consider how their distribution within and across neighborhoods may have different implications for city crime rates. We then describe our study sample, along with the measures used in the study and our research methods. We describe the results, and then conclude.

\section{Theoretical perspective}

Although there are numerous theoretical perspectives on the etiology of crime in various ecological units, two key social constructs are common to nearly all of them: economic 
resources and racial/ethnic composition. Whereas studies have tested the relationship between these two social constructs and crime rates for different units of analysis, fewer studies have considered the possibility that the geographic distribution of these social characteristics within a unit of analysis may have important implications. In short, these measures may not exhibit aggregation invariance (Land, McCall, and Cohen 1990). That is, it may not be enough to simply assume that the relationship between, say, inequality and crime in smaller units of analysis simply sums up to capture the relationship at a larger unit of aggregation. For each of these constructs, we can consider their composition and distribution within neighborhoods, as well as how they are distributed across neighborhoods. We consider the implications of this next.

Economic resources and crime

A bedrock hypothesis of numerous ecological theories of crime is that concentrations of poverty and low economic resources will foster higher levels of crime. Foremost among these theories is social disorganization theory, which posits that neighborhoods with more poverty will have higher rates of crime due to their inability to obtain resources from the larger community to combat difficulties of crime and disorder (Hunter 1995; Shaw and McKay 1942). More recent work has focused on the role of concentrated disadvantage in neighborhoods for bringing about a sense of hopelessness and a consequence resorting to criminal behavior. Much of this literature builds on the insights of Wilson (Wilson 1987), who argued that the migration of middle class black households out of neighborhoods during the 1970s led to a concentration of the truly disadvantaged. Indeed, numerous studies have used cross-sectional neighborhood-level data to test whether neighborhoods with higher levels of poverty have more crime (Crutchfield 1989; Hipp 2007; Krivo and Peterson 1996; McClain 1989; Messner and Tardiff 1986; Warner and Pierce 1993; Warner and Rountree 1997). 
It is important to highlight that studies using larger units of analysis (such as cities) are implicitly assuming that the geographic distribution of poverty does not matter for fostering crime. Thus, it is assumed that a measure of the percent in poverty in the city will predict the level of crime. Such studies rarely posit a specific theoretical mechanism existing at this higher level of aggregation to explain this relationship, but instead often simply assume a degree of scale invariance in which higher levels of poverty in the neighborhoods of a city will lead to higher levels crime in each of them, and this effect will then aggregate up to the city level. Implicit in this approach is the assumption that the relationship between poverty and crime is linear. Studies have also tested the relationship between poverty and crime for larger units of analysis—such as cities, counties, or even MSA’s (Bainbridge 1989; Beyerlein and Hipp 2005; Chamlin and Cochran 1997; Crutchfield, Geerken, and Gove 1982; Gibbs and Erickson 1976; Harer and Steffensmeier 1992; Hipp, Bauer, Curran, and Bollen 2004; Liska and Bellair 1995; Liska, Logan, and Bellair 1998; Messner and Blau 1987; Shihadeh and Ousey 1996).

This assumption of a linear relationship between poverty and crime may not be reasonable given that scholars following William Julius Wilson (Wilson 1987) have posited a threshold effect in which crime increases dramatically in high poverty neighborhoods. If such a threshold relationship exists, the clustering of poverty into a few neighborhoods of a city will have a dramatically stronger effect on the amount of crime in the city overall. That is, research on the urban underclass (Wilson 1987) suggests that certain neighborhoods with particularly high levels of poverty will lead to complete breakdowns in social organization and hence both a heterogeneity in cultural values (Harding 2007) as well as higher rates of crime (Sampson and Wilson 1995). It therefore may be important to take into account the geographic dispersion of poverty in a city. That is, the degree to which residents in poverty are clustered into particular neighborhoods may lead to higher levels of crime in such cities. This implies a nonlinear 
relationship between poverty and crime at the neighborhood level, which would have important implications for the amount of crime in the city overall. Nonetheless, studies have generally failed to test this proposition. One exception is the recent cross-sectional study by Lee and Ousey (2007) viewing the effect of race and class segregation on black homicide rates.

On the other hand, some research suggests that the nonlinear relationship between poverty and crime is actually a diminishing one. That is, crime increases most strongly as poverty increases from relatively low levels, but at higher levels of poverty increasing amounts of poverty have little effect on the amount of crime-essentially, a satiation effect (Hannon 2002). Again, this nonlinear relationship would imply that how poverty is distributed among the neighborhoods of a city would have important implications for the level of crime overall. Inequality

Another branch of research focuses on the importance of the distribution of economic resources for generating higher rates of crime. When focusing on a distributional variable, correctly identifying the unit of analysis is particularly crucial. For example, if two subareas that are each homogeneous in race/ethnicity (but with different racial/ethnic groups across the two neighborhoods) are incorrectly combined into a single neighborhood, this neighborhood will have a relatively high level of heterogeneity. However, if there is in fact a negative relationship between homogeneity and crime rates, and each of these subareas therefore have low crime rates due to this homogeneity, then this combined neighborhood will have low crime rates as well (but a relatively high level of heterogeneity due to improperly combining these two subareas). Therefore, understanding the geographic unit of analysis at which this mechanism operates is crucial.

At the neighborhood level, one perspective argues that this inequality fosters a sense of injustice and subsequent response through higher levels of crime (Agnew 1985; Agnew 1999; 
Jasso 1980). In this view, lower income residents respond to this perceived injustice by lashing out through various violent acts. A second theory positing the importance of inequality on neighborhood crime is the routine activities theory. The routine activities theory posits that a combination of potential targets (the wealthy), motivated offenders (the poor) and the absence of guardians combine to increase the amount of crime in a neighborhood (Cohen and Felson 1979). Although such inequality need not be limited to the local neighborhood, it should be within the distance offenders are willing to travel and thus contained to relatively contiguous neighborhoods.

Another reason why this inequality might have its effects on crime at the neighborhood level is a perspective that builds on the social distance literature insight that households with a degree of social distance between them will be less likely to interact (McPherson, Smith-Lovin, and Cook 2001). A consequence is that households are therefore less likely to interact with one another in high inequality neighborhoods given the difference in economic resources (Hipp and Perrin 2009), and social disorganization theory posits that this lack of interaction will reduce the provision of informal social control in such neighborhoods, resulting in higher rates of crime (Hipp 2007). In this case, it is not one particular group posited to engage in the increased crime activity, but rather there is increased crime activity in general simply because of the reduced ability to monitor the behavior of persons in the neighborhood. Indeed, studies have used crosssectional neighborhood-level data to test whether neighborhoods with higher levels of inequality have more crime (Crutchfield 1989; Hipp 2007).

Other theoretical models posit that the effects of economic inequality play out at a much larger geographic scale than neighborhoods. In this view, when residents form a sense of injustice based on economic inequality they do not simply compare themselves economically to residents living nearby but rather compare themselves to other residents living in a much broader 
geographic area, such as the city or even larger area. This again implies that it will be those with the fewest economic resources who will respond with violence. If this is indeed this case, measuring inequality at the neighborhood-level is too small a scale to appropriately capture this process.

Beyond the possibility of generating a sense of injustice, some scholars have argued that inequality at the geographic level of the city can also affect the degree of solidarity experienced among residents, which can then impact the amount of city-level crime (Putnam 1995). In this view, inequality reduces the solidarity and social capital of a community, which then lowers its resolve to provide the resources necessary to address crime when it becomes a problem in some neighborhoods. This political perspective argues that the level of inequality in a city will reduce the ability for political solutions to problems surrounding crime and disorder in the community (Bollen and Jackman 1985; Rueschemeyer, Stephens, and Stephens 1992; Tolbert, Lyson, and Irwin 1998). In cities with high inequality, the sense of a communal purpose is diminished, and replaced by a sense that each neighborhood within a city is "on its own”. A neighborhood that then begins to suffer a downward spiral does not receive the resources necessary to address these problems, leading to further difficulties over time. To the extent that this troubled neighborhood then impacts the neighborhoods near it through higher rates of crime, the problems spread to wider geographic areas of the city. This can have consequences for the overall rate of crime in the city.

Therefore, studies viewing the relationship between inequality and crime using larger units of analysis, such as cities, counties, or even MSA's are not necessarily assume scale invariance, but instead are at least implicitly arguing that this is the proper unit of analysis at which the mechanism of inequality affects crime rates (Blau and Blau 1982; Chamlin and 
Cochran 1997; Golden and Messner 1987; Harer and Steffensmeier 1992; Kposowa, Breault, and Harrison 1995; Land, McCall, and Cohen 1990; Ousey 1999; Simpson 1985).

This highlights that assuming scale invariance for a measure such as one capturing the distribution of income is more dubious. There is no a priori reason to assume that summing up the inequality levels of neighborhoods in a city will yield the level of inequality in the city overall. It is quite possible for a city to have low levels of inequality within its neighborhoods, but high levels of inequality across them, resulting in differences in the level of inequality across these units of analysis. The possibility that the levels of inequality across the neighborhoods of a city do not necessarily aggregate up to the level of inequality in the city as a whole raises the importance of understanding the geographic distribution of inequality for understanding crime rates. Note that it is logically possible for a city to have a high degree of inequality overall, but virtually no inequality within its neighborhoods if there is complete segregation based on income level. This suggests the need to simultaneously test the overall level of inequality in a city with the average level of inequality in its neighborhoods in order to tease apart these competing perspectives. Thus, the geographic dispersion of inequality in a city may have important implications for the amount of crime and how it changes over time. Nonetheless, this has not been tested on cross-sectional data, much less longitudinal data viewing changes in city crime over time.

Another possibility, that has rarely been considered, is that the context of the overall level of inequality in the city may be important for understanding the effects of inequality within neighborhoods on crime rates. That is, in cities with high rates of overall inequality, the awareness of such injustice may be heightened. In such cities, economic segregation of residents into separate neighborhoods might not reduce the amount of crime. Instead, the salience of inequality in such cities may even be heightened by the sense of separateness between 
neighborhoods, leading to enmity between impoverished residents living in some neighborhoods towards more economically advantaged residents living in different neighborhoods. In this case, the economic inequality would get played out on a larger scale as competition between neighborhoods. In some ways, this view builds on the defended neighborhood literature, in that neighborhoods would identify themselves based on their similar level of economic resources, and come to identify others with different levels of economic resources as outsiders (Suttles 1972). Although this defensive posture on the part of individual neighborhoods would be geared towards reducing crime, the overall milieu of competition between neighborhoods might lead to higher crime rates overall. In contrast, in cities with low levels of inequality, the differences in economic resources between residents would be less salient. In this case, the micro effect of segregation as postulated by routine activities theory and social disorganization theory may well be evidence in the neighborhoods within such cities, leading to higher rates of crime in neighborhoods with more inequality. We are aware of no tests of these hypotheses.

\section{Race/ethnicity and crime}

A second key characteristic for understanding crime rates is the racial/ethnic composition of the city, as well as its spatial distribution. Some theoretical perspectives posit that the presence of racial/ethnic minorities will lead to higher rates of crime, due to a culture of violence among racial/ethnic minorities (Wolfgang and Ferracuti 1967). In this literature, it is not the degree of mixing among race/ethnicities, but rather simply the presence of racial/ethnic minorities, that leads to more crime. One perspective argues for a strictly cultural explanation, in which racial/ethnic minorities develop a culture in which criminal activity is not actively sanctioned (Wolfgang and Ferracuti 1967). This perspective implicitly posits a rather homogeneous culture for such minority groups, and therefore might be expected to exhibit a degree of scale invariance. 
A second theoretical perspective argues for a combination structural/cultural explanation (Sampson and Wilson 1995). In this perspective, a larger systemic bias that relegates some members of these minority groups to the most disadvantaged neighborhoods brings about an isolation from the larger society and hence the development of alternative cultural values in these neighborhoods. This structural disadvantage leads to economic dislocation and unemployment in minority-dominant neighborhoods, resulting in more broken households that decrease the ability to provide social control to reduce the amount of crime (Sampson 1987). There are important implications of this theory: first, there is little reason to expect this effect to scale up to the level of the city. That is, it is not posited that these cultural values are shared by all members of these minority groups, but rather only those in an economically disadvantaged position. Second, it is not even enough to consider the combination of the economic disadvantage of such minority members, but rather the notion of the geographic distribution of these disadvantage minorities within the city is explicitly posited in this theory. This implies the importance of considering the geographic concentration of racial/ethnic groups across the city landscape.

The empirical evidence generally shows a positive relationship between the presence of minority residents and crime rates, regardless of the unit of analysis. Numerous studies have found that the presence of more minority residents in neighborhoods is associated with higher crime rates (Crutchfield 1989; Hannon and Knapp 2003; Krivo and Peterson 1996; Ouimet 2000; Peterson, Krivo, and Harris 2000; Roncek 1981). Some studies have found a positive effect for the presence of racial/ethnic minorities even when accounting for the level of racial/ethnic heterogeneity (Hipp 2007; Roncek and Maier 1991). Additionally, numerous studies have tested the relationship between the percentage of African-Americans or non-whites in a city and rates of crime, though various theoretical explanations have been given for such an effect (Beyerlein 
and Hipp 2005; Chamlin and Cochran 1997; Kawachi, Kennedy, Lochner, and Prothrow-Stith

1997; Kovandzic, Vieratis, and Yeisley 1998; Land, McCall, and Cohen 1990; Liska and Bellair

1995; Messner 1983b; Miethe, Hughes, and McDowall 1991; Ousey 1999; Sampson 1985;

Wilkinson 1996).

Racial/ethnic heterogeneity

Another body of literature suggests that it is not the simple presence of racial/ethnic minorities that is important for generating higher rates of crime, but rather the mixing of different racial/ethnic groups. This literature builds on the social disorganization theory that higher levels of racial/ethnic heterogeneity in neighborhoods will affect crime through the mechanisms of reduced social interaction and subsequent less informal social control (Sampson and Groves 1989). This focus on the effect on social interactions implies that this racial/ethnic heterogeneity should be measured at the scale of neighborhoods. Indeed, studies have tested and found that racial/ethnic heterogeneity in neighborhoods reduces social interactions among residents (Lowenkamp, Cullen, and Pratt 2003; Warner and Rountree 1997). Other research has shown that racial/ethnic heterogeneity is associated with higher neighborhood crime rates (Bellair 1997; Hipp 2007; Sampson and Groves 1989; Shaw and McKay 1942; Veysey and Messner 1999; Warner and Pierce 1993; Warner and Rountree 1997).

In contrast to theories focusing on the effect of racial/ethnic mixing on social interactions at the neighborhood level, theories adopting a political perspective focus on larger units of analysis such as cities. For example, one perspective argues that greater levels of racial/ethnic heterogeneity reduce the community's political resolve to work together to address crime problems (Putnam 2000). This implies that it is the level of heterogeneity in the city that will be important for affecting the rate of crime, and not the level of heterogeneity within neighborhoods. Of course, the robust evidence that heterogeneity within neighborhoods leads to 
more crime suggests the possibility that both processes might be at work. Few studies have actually included a measure of racial/ethnic heterogeneity in their models, though two studies did so and found significant effects in counties (McVeigh 2006), and cities (Hipp, Bauer, Curran, and Bollen 2004). Some studies have tested the possible effect of city level racial/ethnic heterogeneity on crime rates by including a quadratic effect for percent African-American (Messner 1983a; Williams 1984).

Similar to the issues discussed above regarding the distribution of income, when discussing the degree of racial/ethnic mixing it is important to properly define the proper geographic unit of analysis. These considerations highlight an important distinction: a city with a high rate of overall ethnic heterogeneity could in principle have completely homogeneous neighborhoods. Therefore, the assumption of scale invariance of the effect of racial/ethnic heterogeneity at the neighborhood level is not reasonable given that there can be cities with little heterogeneity within neighborhoods, but high levels of heterogeneity across neighborhoods. Indeed, a long line of studies in the segregation literature have highlighted that cities tend to experience high levels of segregation by race/ethnicity. In the most extreme case of segregation, a city could have neighborhoods that were completely homogeneous, but nonetheless a high level of heterogeneity overall.

This suggests a key test: if racial/ethnic heterogeneity is more important at the neighborhood level, then a measure of the average level of heterogeneity in the tracts of a city will have a stronger effect on the amount of crime and its trajectory over time than will a measure of the level of racial/ethnic heterogeneity in the city. We are aware of no studies that have tested this possibility in either a cross-sectional or a longitudinal framework. While some studies have included a measure of the level of segregation in the city in predicting crime along with a measure of percent nonwhite (Liska and Bellair 1995) or percent African-American 
(Ousey 1999), such an approach does not measure the effect of racial/ethnic heterogeneity at the city level. Similarly, studies including a segregation measure along with no other measures of racial/ethnic composition are not able to speak to this question (Shihadeh and Flynn 1996). That is, failing to simultaneously take into account the average level of racial/ethnic heterogeneity in the tracts of the city precludes teasing apart these effects.

The possible importance of racial/ethnic mixing when measured at differing geographic units of analysis suggests that focusing on only one geographic unit of analysis may miss the larger picture. Thus, whereas the degree of segregation in a city describes the distribution of racial/ethnic groups across the neighborhoods of the city, the racial/ethnic heterogeneity of the city accounts for the general level of mixing. Thus, a city with low overall racial/ethnic heterogeneity with low segregation would have neighborhoods that have very similar racial/ethnic compositions to the larger city, and therefore there would be racial/ethnic mixing within the neighborhoods of the city. On the other hand, a city with low overall racial/ethnic heterogeneity and high segregation would have neighborhoods which are extremely homogeneous, but the ones containing minority members would tend to be isolated into ethnic enclaves. A city with high overall racial/ethnic heterogeneity and high segregation would also have neighborhoods that are very homogeneous, but there would be a much larger number of minority dominated neighborhoods. Finally, a city with high overall racial/ethnic heterogeneity and low segregation would have many neighborhoods with high levels of racial/ethnic heterogeneity.

Given our above theoretical considerations, what does each of these scenarios imply? To the extent that racial/ethnic heterogeneity in neighborhoods has important implications for neighborhood crime rates (and would then sum up to city-level crime rates), then cities with lower levels of segregation will have higher rates of crime. This is because this reduced 
segregation brings different groups into contact in neighborhoods, affecting the social interactions among these residents. The city with higher overall heterogeneity but lower segregation would therefore be posited to have the highest rate of crime in this scenario. In contrast, cities with higher levels of segregation would have lower crime rates, given that the neighborhoods within the city would have low heterogeneity.

Similar to the argument regarding the effect of neighborhood inequality within the context of city-level inequality, it may be that the effect of racial/ethnic heterogeneity depends on the city context within which it occurs. That is, in cities with a high level of racial/ethnic heterogeneity, race/ethnicity might be particularly salient. In such a context, the segregation of residents into different neighborhoods based on race/ethnicity may be quite apparent to residents, leading to a sense of competition between neighborhoods. In this case, the notion of defended neighborhoods (Suttles 1972) would revolve around the race/ethnicity of the residents. In this case, this segregation may lead to heightened crime events from residents in one neighborhood upon residents in other neighborhoods. In contrast, in a city with a low level of racial/ethnic heterogeneity, race/ethnicity may be less salient in the overall context. This would lead to less crime between neighborhoods. Nonetheless, in such cities, racial/ethnic heterogeneity within neighborhoods would increase neighborhood crime rates as postulated by social disorganization theory.

Despite the importance of these questions, we have scant empirical evidence. While neighborhood studies have viewed the effect of race/ethnicity and economic resources on crime rates, and city-level studies have viewed the effect of these two constructs when measured at the city-level, research has not considered the spatial distribution of these constructs at the city level. Furthermore, we lack empirical evidence regarding how this spatial distribution of these constructs affects crime trajectories of cities over a long time period. Furthermore, in addition to 
the paucity of studies viewing these questions cross-sectionally, even less research has viewed these questions longitudinally. This study addresses these lacunae.

\section{Data and methods}

A challenge for studies viewing city trajectories of crime is the need to compare cities at similar "developmental” levels. Whereas trajectory models have frequently been used in the child development literature, researchers are aware of the need to compare children's trajectories at similar age levels. An analogous issue arises for cities: the issues facing older rust belt cities arguably are different from those facing newer sprawling cities in the south and west. This implies that it is not appropriate to simply compare the trajectories of cities from these different milieus over a specific period of time. Rather, it is more appropriate to compare a group of cities over the same time period that developed at a similar point in time. By adopting this approach, we are effectively controlling for other city characteristics in isolating the effect of economic and racial/ethnic distribution across households and neighborhoods in cities for trajectories of crime rates. Thus, the goal of these analyses is not to compare city trajectories in different types of metropolitan areas — which would necessitate using metropolitan areas with different developmental trajectories — but rather to compare areas that developed during a similar time period but nonetheless may have differences across them in how this development occurred. This allows comparing how these trajectories differ based on the distribution of economic resources and racial/ethnic composition across cities. ${ }^{1}$

We analyzed city-level data from the 1970-2000 period to understand crime trajectories of cities in counties/areas that have experienced a booming population in the post-World War II era ("boomburbs"). The term "boomburbs" has been coined to describe these booming suburbs

\footnotetext{
${ }^{1}$ We also estimated additional models in which we included indicator variables for 13 of the 14 areas. In these subsidiary analyses, we are comparing cities within the same metropolitan area. The results were substantively similar to those presented here, so we do not pursue them further.
} 
(Lang and Simmons 2001). They face similar issues as all have experienced rapid growth of tract-style housing that sprawls at a relatively low density over large areas away from a regional center. The following counties/areas are included in the study, with their population growth rate since the beginning of their boom period in parentheses: Atlanta (GR=18.2); Dallas (GR=3.6); Denver (GR=9.0); Houston (GR=4.2); Las Vegas (GR=28.5); Miami: (GR=4.6); Orange County, CA (GR=13.2); Orlando (GR=7.8); Phoenix (GR=9.3); Riverside (GR=9.1); San Bernardino (GR=6.1); San Diego (GR=5.1); Silicon Valley (Santa Clara) (GR=5.8); Tampa/St. Pete $(\mathrm{GR}=5.8)$.

Dependent variables

We employed crime data from the Uniform Crime Reports of cities over the 1970-2000 period (downloaded from http://www.icpsr.umich.edu/NACJD/index.html). Our key outcome measures are crime rates of these cities for four key types of Type I crimes: aggravated assaults, robberies, burglaries, and motor vehicle thefts. These rates are computed per 1,000 residents. Independent variables

We used data from the U.S. decennial censuses to construct our key exogenous measures. At the city level, we computed the percentage of two key racial/ethnic minority groups: AfricanAmerican and Latino. We constructed a measure of the racial/ethnic heterogeneity in the city with a Herfindahl index (Gibbs and Martin 1962: 670) of five racial/ethnic groups (white, African American, Latino, Asian, and other race), which takes the following form:

$$
H=1-\sum_{j=1}^{J} G_{j}{ }^{2}
$$

where $G$ represents the proportion of the population of ethnic group $j$ out of $J$ ethnic groups.

We computed economic resources as the median income in the city. We measured overall income inequality with the Gini coefficient, which is defined as: 


$$
G=\frac{2}{\mu n^{2}} \sum_{i=1}^{n} i x_{i}-\frac{n+1}{n}
$$

where $x_{i}$ is the household's income for 1999 as reported in the 2000 census, $\mu$ is the mean income value, the households are arranged in ascending values indexed by $i$, up to $n$ households in the sample. Because the data are binned (as income is coded into various ranges of values), we take this into account by utilizing the Pareto-linear procedure (Aigner and Goldberger 1970; Kakwani and Podder 1976), which Nielsen and Alderson (1997) adapted from the U.S. Census Bureau. $^{2}$

We also constructed key measures that account for the spatial distribution across the tracts in a city. To capture the degree of racial/ethnic segregation in the city, we computed Theil's information theory measure $(H)$ of multiple groups (Theil 1967) for the five racial/ethnic groups in each city. To calculate this, we first computed the entropy score of the city $(E)$ as:

$$
E=\sum_{j=1}^{J}\left(\Pi_{j}\right) \ln \left[1 / \Pi_{j}\right]
$$

where $\Pi_{j}$ represents the racial/ethnic group j's proportion of the entire city population, and $\ln$ is the natural log. We then computed the entropy score of each census tract $\left(E_{i}\right)$ as:

$$
E_{i}=\sum_{j=1}^{J}\left(\Pi_{j i}\right) \ln \left[1 / \Pi_{j i}\right]
$$

where $\prod_{\mathrm{ji}}$ represents the racial/ethnic group j's proportion of tract $i$ 's population. Using these two measures, we calculated Theil's $\mathrm{H}$ index $(\mathrm{H})$ for the entire city as the weighted average deviation of each tract's entropy from the city-wide entropy:

$$
H=\sum_{i=1}^{I}\left[\frac{t_{i}\left(E-E_{i}\right)}{E T}\right]
$$

\footnotetext{
${ }^{2}$ We used the prln04.exe program provided by Francois Nielsen at the following website: http://www.unc.edu/ nielsen/data/data.htm.
} 
where $t_{i}$ is the population of tract $i, T$ is the city population, $E$ is the city area entropy, $E_{i}$ is tract i's entropy of $I$ tracts. This measure ranges from a value of 0 when all tracts contain the same composition as the overall city, to 1 when all areas contain a single group only, representing complete segregation.

To assess whether income inequality is more important at the tract level rather than at the city level, we computed the Gini value of household income in each tract using the same procedure as described above for measuring inequality at the city level. We then compute the average level of inequality across all tracts in the city to capture these neighborhood effects. To measure economic segregation in these cities, we computed the variance in logged median income across the tracts in a city.

To assess whether racial/ethnic heterogeneity is more important at the tract level rather than at the city level, we computed the level of racial/ethnic heterogeneity in each tract using the same procedure as described above for measuring heterogeneity at the city level. We then computed the average level of heterogeneity across all tracts in the city.

We included several additional city-level measures to minimize the possibility of spurious results. Because homeowners have a greater investment in the neighborhood and hence likely engage in more crime-reducing behavior, we computed the percentage of city households who own their residence. Because broken families are posited to reduce crime-inhibiting activities we calculated the proportion of single parent households in the city. To capture increased crime possibilities of abandoned buildings, we included the percentage of residential units that are occupied. We also included the percent unemployed in the city to capture these possible effects. We accounted for crowding by including a measure of the percentage of households living in crowded conditions (defined as more than one person per room). We accounted for population size, as prior evidence suggests that larger cities will suffer from higher 
rates of crime (Baumer, Lauritsen, Rosenfeld, and Wright 1998; Liska and Bellair 1995; Ousey 1999; Sampson 1985; Sampson 1987; Williams and Flewelling 1988). Given that recent work by Land and colleagues has suggested that college towns exhibit a different trajectory of crime, we included a measure of the percentage of young residents (defined as the percentage of residents aged 19 to 29) who attend college. To account for the fact that a few of these cities are somewhat older than the others in this sample of relatively young cities, we included a measure of the average age of the housing structures in the city.

In the equations predicting the change in crime over the decade, we computed differenced versions of the above measures. That is, we computed the difference in the measure at the beginning of the decade from the value at the end of the decade. The one exception is that instead of computing the change in racial/ethnic heterogeneity (which can have differential meaning whether the city is at the beginning or near the end of a transition period from one dominant group to another), we computed a measure of the racial/ethnic churning (EC) in the city (Pastor, Sadd, and Hipp 2001). This captures the degree to which a city $k$ undergoes racial/ethnic change during the decade by:

$$
E C_{k}=\sqrt{\sum_{1}^{J}\left(G_{j t}-G_{j t-1}\right)^{2}}
$$

where $\mathrm{G}$ represents the proportion of the population of racial/ethnic group $j$ out of $J$ racial/ethnic groups at time $t$ and time $t-1$. This is a sum of squares of differences, and we take the square root to return it approximately to the original metric.

\section{Methods}


This document is a research report submitted to the U.S. Department of Justice. This report has not been published by the Department. Opinions or points of view expressed are those of the author(s) and do not necessarily reflect the official position or policies of the U.S. Department of Justice.

We use latent trajectory models to describe the trajectories of violent and property crime for the cities in the study over this time period (Bollen, Christ, and Hipp 2003; Bollen and Curran 2006). ${ }^{3}$ This implies the following equation:

$$
\mathrm{y}_{t j j}=\alpha_{i j}+\lambda_{t} \beta_{i j}+\lambda_{t}^{2} \beta^{2}{ }_{i j}+\varepsilon_{t i j}
$$

where $\mathrm{y}$ is the crime rate at time $t$ in city $i$ in county $j, \alpha$ is a random intercept that varies over cities within a county, $\beta$ is a random slope that varies over cities in a county and has a $\lambda$ effect on $y$ (where lambda is structured to take into account time), $\beta^{2}$ is an optional random quadratic term that varies over cities in an area with a $\lambda^{2}$ effect on $y$, and $\varepsilon$ is a disturbance term for each city at each time point with an assumed normal distribution and mean of zero. Given the size of these cities, the logged crime rate distributions approximate a normal distribution, meaning that treating these as continuous measures rather than counts yield appropriate results. This is advantageous because current software is limited in its ability to estimate a Poisson outcome in such multivariate analyses. ${ }^{4}$ In this framework, the $\lambda$ 's can be structured to estimate various

\footnotetext{
${ }^{3}$ We use a latent trajectory model here estimated within the structural equation model (SEM) framework. Nonetheless, we could have estimated trajectory models with a multilevel software package and obtained identical results. This notion is not new, as scholars have long been aware that HLM and SEM will yield identical results when the data are balanced - that is, there are an equal number of cases in each higher-level unit (Curran 2003). One consequence is that there are numerous studies showing that HLM and SEM will yield identical estimates for such trajectory models (Chou, Bentler, and Pentz 1998; Guo and Hipp 2004; MacCallum, Kim, Malarkey, and Kiecolt-Glaser 1997; Mehta and West 2000; Raudenbush 2001). More recent work has shown that it is possible to estimate multilevel models in SEM even when the data are not balanced (Bauer 2003; Lee and Tsang 1999). For a nice didactic paper showing how HLM and SEM can be used to obtain identical results, see Bauer (Bauer 2003). This paper illustrates that the HLM approach uses a dataset that is swung "long” in which each observation is a level one unit, whereas the SEM approach uses a dataset swung "wide" in which each observation is the highest level unit. Another approach adopts a cross-sectional panel design. However, this approach does not explicitly incorporate how each city changes over time in crime rates, and therefore is less useful for the analyses conducted here.

${ }^{4}$ Another approach would estimate growth mixture models, or a variant of them: latent class growth analysis of Nagin and Land, as implemented in Proc Traj in SAS. Although this approach would allow estimating multiple groups, our interest here is not in teasing apart the existence of such groups and the philosophical debates over their reification (for a nice discussion of these issues, see Bauer and Curran 2003; Bauer and Curran 2004). Although the Proc Traj approach allows estimating a Poisson outcome, this approach imposes other assumptions that are arguably far more implausible than the assumption adopted here that the continuous logged measure will approximate a normal distribution (indeed, our outcome variables appear to be quite normally distributed). For instance, Proc Traj would assume that there is no variability in crime trajectories across cities within a "group". We agree with the viewpoint stated elsewhere that this assumption seems quite unreasonable (Bauer and Curran 2003; Hipp and Bauer 2006; Muthén and Muthén 2000; Muthén 2001).
} 
forms of trajectory: linear, logarithmic, or even unstructured (in which only the first and last time points are specified, and the remaining $\lambda$ 's are estimated) (for a more complete discussion of such modeling, see Bollen and Curran 2006). Note that more elaborate nonlinear functions can be estimated—such as exponential or Gompertz curves—and additional random slope terms can be included to estimate cubic trajectories over time, or even higher order polynomials. However, we constrain our perspective to more simple polynomial models here because we do not hypothesize these trajectories heading to any particular asymptote.

The second step in the analyses after estimating the trajectories of crime in cities within counties is attempting to explain these differing trajectories. This uses characteristics of a city to explain the level of crime at one point in time, and changes in the characteristics of a city to explain the trajectory of crime over the following decade. This implies augmenting the previous equation to yield these second-level models:

$$
\begin{aligned}
& \alpha_{i j}=\kappa_{\alpha}+\Gamma_{\alpha} X_{i j}+\zeta_{1 i j} \\
& \beta_{i j}=\kappa_{\beta}+\Gamma_{\Delta \beta} \Delta X_{i j}+\zeta_{2 i j} \\
& \beta^{2}{ }_{i j}=\kappa_{\beta}^{2}+\Gamma_{\Delta \beta}{ }^{2} \Delta X_{i j}+\zeta_{3 i j}
\end{aligned}
$$

where $\alpha, \beta$ and $\beta^{2}$ are as defined before, the $\kappa$ 's represent the fixed intercepts for these random terms, $\mathrm{X}$ is a matrix of our city-level variables of interest which has $\Gamma_{\alpha}$ effect on the random intercept (the amount of crime in the city at the beginning of the decade), $\Delta \mathrm{X}$ is a matrix of the changes in our city-level variables of interest over the decade which has a $\Gamma_{\Delta \beta}$ effect on the random slope and a $\Gamma_{\Delta \beta}^{2}$ effect on the random quadratic term (capturing the change in crime in 
This document is a research report submitted to the U.S. Department of Justice. This report has not been published by the Department. Opinions or points of view expressed are those of the author(s) and do not necessarily reflect the official position or policies of the U.S. Department of Justice.

the city over the decade), and the $\zeta$ 's are disturbance terms with an assumed zero mean and normal distribution. ${ }^{5}$

Note that it is possible to constrain the coefficients in the $\Gamma$ matrices to be equal over all three decades. We assessed whether this was appropriate by estimating models first allowing these coefficients to vary over decades, and then estimating models constraining them to be equal. Given our large sample size, it is more informative to compare these models using the Bayesian Information Criterion (BIC). The results showed that for nearly all of the models, a more satisfactory BIC value was obtained when constraining these coefficients equal over the decades. That is, the parsimony in the model from estimating fewer coefficients outweighed any gain in absolute model fit. These results imply that these effects are relatively constant over the decades of the period of study.

\section{Results}

We begin by focusing on the main effects of our measures in these models, and later turn to the question of possible interaction effects between inequality and income segregation, and between heterogeneity and segregation. Turning to the results using aggravated assault as an outcome, we see that whereas cities with a higher proportion of African Americans have higher levels of aggravated assault cross-sectionally (the first column of Table 2), there is no evidence

\footnotetext{
${ }^{5}$ Handling possible spatial autocorrelation in latent trajectory models is not straightforward. Nonetheless, although there are two possible forms of spatial effects — a spatial autocorrelation (or, error) effect, or a spatial lag effect — the consequences of these are not deleterious for our study. If spatial autocorrelation exists (in which there is an additional relationship between the residuals of neighboring tracts), only the standard errors are affected by ignoring this problem. In general, ignoring this inflates the standard errors, suggesting that our test here is somewhat conservative, and that accounting for spatial autocorrelation - if it is indeed present-would simply strengthen the significance of the observed relationships (Anselin 2002). If the data contain a spatial lag effect (in which the crime rate in one city increases crime in adjacent cities), then ignoring this would imply that we are capturing total effects of our predictors, rather than direct effects. That is, the presence of poverty in a city may be associated with higher levels of crime, and these higher levels of crime then impact the amount of crime in adjacent cities. This implies that the presence of poverty in one city indirectly increase the amount of crime in adjacent cities. Because our goal is not to parse apart these direct and indirect effects, we suggest that these total effects are of interest to academics and policy makers.
} 
that the change in African Americans in a city over a decade affects the change in the aggravated assault rates during the same decade (the second column in Table 2). On the other hand, although we see no evidence that the level of racial/ethnic heterogeneity affects the aggravated assault rate cross-sectionally, we do see that higher levels of ethnic churning during the decade are associated with greater increases in aggravated assault rates during the decade $(b=.003)$.

$$
<<<\text { Table } 2 \text { about here }>>>
$$

The effects for economic resources are weaker. There is no evidence that the average family income impacts aggravated assault rates, nor that how income is changing affects the change in these assault rates. Likewise, the unemployment rate appears unrelated to aggravated assault rates and how they change. There is some evidence in this model that cities with higher rates of single parent households have higher aggravated assault rates, though increasing percentages of single parent households are actually associated with a downward trend in assault rates over time.

We do see evidence that economic inequality has important effects on aggravated assault rates. Cities with higher levels of inequality have higher aggravated assault rates. Furthermore, cities that are experiencing an increase in the level of inequality simultaneously experience an increasing aggravated assault rate.

We briefly note the effects for our control variables. Although there is no evidence that higher levels of homeownership affect assault rates, we do see that more vacant units lead to higher assault rates at a point in time. However, crowding in units does not affect assault rates. As expected, cities with more college students have lower assault rates. Older cities (as measured by the age of the housing stock) have higher aggravated assault rates.

In model 2, we ask whether the level of income segregation in the city affects aggravated assault rates. There is no evidence here of such an effect. 
In model 3, we focus on the effect of racial/ethnic segregation. We see strong evidence that racial/ethnic segregation has implications for aggravated assault rates. Cross-sectionally, there are strong nonlinear effects, which we plot in Figure 1. At the very lowest levels of segregation, aggravated assault rates are quite low. However, as segregation begins to increase from these lowest levels, aggravated assault rates increase sharply. This effect eventually reverses slightly at the very highest levels of segregation. Thus, even mid-range levels of segregation result in quite sharp increases in aggravated assault.

$<<<$ Figure 1 about here $>>>$

\section{Predicting robbery rates}

Turning to the models predicting robbery rates, the pattern of results is generally similar. We see strong race/ethnicity effects: cities with a higher percentage of African Americans have higher robbery rates. And cities undergoing an increase in the percent African American experience a simultaneous increase in the robbery rate. We again see that whereas racial/ethnic heterogeneity in the city is not associated with higher robbery rates, ethnic churning over a decade accompanies increasing robbery rates over the same decade.

$$
<<<\text { Table } 3 \text { about here }>>>
$$

We again see some effects for our economic indicators. Whereas the average family income is not associated with higher robbery rates cross-sectionally, cities undergoing falling average income over a decade experience increasing robbery rates. We also see a similar pattern for single parent households as was observed in the aggravated assault models: cities with higher percentages of single parent households have higher robbery rates, controlling for the other measures in the model, but an increase in the presence of single parent households actually results in a decrease in the robbery rate in the dynamic equation. Again, there is no evidence that 
the unemployment rate affects this type of crime, nor that changes in the unemployment rate affect changes in robbery rates over the decade.

We do see evidence that economic inequality has important effects on robbery rates in the cross-sectional equation. Cities with higher levels of inequality have higher robbery rates. This is an explosive relationship that shows even stronger effects at higher levels of inequality, as can be seen when we graph this effect in Figure 2.

\section{$<<<$ Figure 2 about here $>>>$}

For the control variables, we see some evidence that the presence of more homeowners reduces the robbery rate both cross-sectionally and that an increase in owners during the decade reduces the robbery rate over the decade in the dynamic equation. And although the presence of vacant units does not have an effect, the presence of more crowded households increases the robbery rate in the cross-sectional equation.

In model 2, we see that cities with higher levels of income segregation have higher robbery rates. There is no evidence of a dynamic effect, as increasing levels of income segregation during the decade do not lead to increasing robbery rates.

In model 3, we see some evidence that higher levels of racial/ethnic segregation result in higher robbery rates. On the other hand, the dynamic effect is in the opposite direction, as cities experiencing increasing levels of racial/ethnic segregation experience falling robbery rates during the same decade.

Predicting burglary rates

We next turn to one form of property crime: burglary. We see evidence that cities with more African Americans have higher burglary rates. As well, cities experiencing an increase in percentage African Americans simultaneously experience an increase in the burglary rate. There 
is no evidence that racial/ethnic heterogeneity is associated with higher burglary rates, nor that ethnic churning is associated with increasing burglary rates.

$$
<<<\text { Table } 4 \text { about here }>>>
$$

The pattern for the economic indicators variables is similar to the violent crime results. There is no evidence that the average level of income affects the burglary rate. Consistent with the violent crime models, cities with higher rates of single parent households have higher burglary rates, whereas the effect in the dynamic model is the opposite: cities undergoing an increase in the percentage single parent households actually experience a decrease in the burglary rate. On the other hand, we do see evidence here that increasing unemployment rates over the decade are accompanied by increasing burglary rates.

There is strong cross-sectional evidence here that cities with higher levels of inequality have higher burglary rates. This is an explosive effect which shows the most pronounced effects for cities with the highest rates of inequality, as shown in Figure 3. As seen in this figure, changes in the level of inequality for cities at or below the average level of inequality generally have quite modest effects, increases in the level of inequality for cities above the average level of inequality show dramatically increasing burglary rates.

\section{$<<<$ Figure 3 about here $>>>$}

Among the control variables, we see that cities experiencing an increase in the percentage homeowners are more likely to experience a decreasing burglary rate. And whereas a higher vacancy rate at a point in time is associated with higher burglary rates, cities undergoing an increasing vacancy rate experience a simultaneous decrease in the burglary rate. Thus, this appears to be more of a long run equilibrium effect, rather than a dynamic one. Likewise, cities experiencing an increasing amount of crowding actually experience a falling burglary rate. And 
the presence of college students is associated with lower burglary rates, whether measured crosssectionally or in the dynamic equation.

Turning to the additional models accounting for racial/ethnic and economic segregation, we see that income segregation has a strongly negative effect on burglary rates in model 2 . This effect is plotted in Figure 4, and shows that whereas increasing segregation from very low levels to average levels has very little impact on the burglary rate, increasing it from average levels to high levels strongly reduces the burglary rate.

\section{$<<<$ Figure 4 about here $>>>$}

In model 3, we see quite strong effects for racial/ethnic segregation, though they differ based on whether we are viewing the cross-sectional equation or the dynamic equation. In the cross-sectional model, cities with higher levels of racial/ethnic segregation have higher burglary rates. In contrast, the dynamic equation shows that cities undergoing an increase in the level of segregation actually experience a decrease in the burglary rate. Thus, there appears to be a difference between whether a city is currently undergoing a change in the degree of segregation, or whether it has achieved a new equilibrium point.

\section{Predicting motor vehicle theft rates}

Turning to motor vehicle theft, the racial/ethnic effects for this type of crime differ from the other types. There is no evidence that motor vehicle thefts are more likely to occur in cities with a higher percentage of African Americans, or an increasing percentage of African Americans. There is also no evidence that racial/ethnic heterogeneity or churning affects this type of crime. On the other hand, this is the only crime type that is positively associated with the presence of Latinos: cities with a higher percentage of Latinos have a higher motor vehicle theft rate in the cross-sectional equation. 
There is no evidence that the economic indicators of average income or unemployment rate affect the level of motor vehicle thefts. We do see that cities with more single parent households have higher rates of motor vehicle thefts.

Although there is no evidence that cities with higher levels of inequality have higher motor vehicle theft rates, we do see significant effects in our dynamic specification. Cities with increasing levels of inequality experience increasing motor vehicle theft rates over the same decade.

Among the control variables, we see that the presence of homeowners reduce the motor vehicle theft rate in the cross-sectional model. There is little evidence that vacant units or crowded units affect this type of crime.

In model 2 we ask about the effect of income segregation. This effect is effectively a linear negative one in which higher levels of income segregation actually results in lower motor vehicle theft rates. Thus, this positive quadratic effect is only diminishing the negative main effect, given the distribution of this variable.

In model 3, we see no relationship between racial/ethnic segregation and motor vehicle theft rates.

\section{Interaction of income segregation and inequality}

We next turn to a key focus of this study: to what extent are our measures of income and racial/ethnic segregation moderated by the level of racial/ethnic heterogeneity or income inequality in the city? We first focus on the question of the interaction between the level of inequality in the city and the level of economic segregation. We present the results as figures to aid in interpretation. We plot each of these variables at their mean values, and at values one standard deviation above and below the mean. 
We see strong interaction effects for these economic measures. In the model predicting aggravated assault, we see in Figure 5 that for cities with low levels of inequality, income segregation actually has a negative effect on aggravated assault rates. Thus, segregating households by their income level does not have negative consequences in cities with relatively low levels of inequality. In such cities, the neighborhoods have low levels of inequality, which presumably leads to less aggravated assault in them, resulting in a lower aggravated assault rate in the city overall. On the other hand, in cities with average levels of inequality, aggravated assault rates increase as the degree of economic segregation increases. This effect is accentuated even more in cities with high levels of inequality. Thus, we see that in cities with very high levels of inequality assault rates will be quite low if there are very high levels of mixing of economic groups in neighborhoods. In contrast, cities with very high levels of inequality and very high levels of economic segregation—walled off fortresses of wealth—will have the highest assault rates of any of these combinations. These neighborhoods presumably lead to enmity between them, increasing rates of overall crime.

$$
<<<\text { Figure } 5 \text { about here }>>>
$$

Turning to the results for robbery rates, we see that they are very similar to those for aggravated assault. Again, at low levels of inequality, economic segregation actually reduces the robbery rate in the city overall, as seen in Figure 6. Thus, we see here that the cities with the lowest robbery rates are those with relatively low inequality, but high levels of segregation for the inequality that does exist. Thus, economic segregation does not seem to matter in this overall ecology, whereas the low levels of inequality reduce the robbery rate. And whereas economic segregation does not seem to matter much for cities with average levels of inequality, the effect reverses in high inequality cities: in these cities, increasing levels of economic segregation increase the robbery rate. Again, the cities with the highest robbery rate are those with high 
levels of inequality and very high levels of economic segregation-again, the walled off fortresses of wealth. This implies that inequality becomes salient in such cities, leading to defended neighborhoods as enmity grows between neighborhoods leading to higher overall levels of crime.

$<<<$ Figure 6 about here $>>>$

Turning to our two property crime types, we see in Figure 7 for burglary rates and in Figure 8 for motor vehicle theft rates that economic segregation reduces these crime types in cities with very low levels of inequality. As a consequence, the obverse is the case: cities with very low levels of inequality but with much mixing of income groups in neighborhoods actually have relatively high levels of these two types of property crime. Again, it appears that the effect of inequality within neighborhoods has its strongest effect in cities in which overall inequality is relatively low, and therefore less salient. For both of these crime types, this effect of economic segregation is much weaker in cities with average levels of inequality. And in cities with very high levels of inequality, economic segregation greatly increases the motor vehicle theft rate, as seen in Figure 8. For burglary rates the story is slightly different, as high inequality cities lead to very high burglary rates regardless of the level of economic segregation. Thus, whereas economic segregation can actually reduce burglary rates in cities with low levels of inequality, no such effect is detected in cities with high levels of inequality.

$$
<<<\text { Figures } 7 \text { and } 8 \text { about here }>>>
$$

\section{Interaction of racial/ethnic segregation and racial/ethnic heterogeneity}

We next ask whether the effect of racial/ethnic segregation in the city is moderated by the level of heterogeneity in the city. We see a similar pattern to that observed for inequality and economic segregation. In the model predicting the aggravated assault rate, we see in Figure 9 that segregation actually reduces the aggravated assault rate when it occurs in a city with a 
relatively low level of racial/ethnic heterogeneity. In fact, cities with the lowest aggravated assault rates are those with very low heterogeneity, but high levels of segregation for these small numbers of minority members. As an alterative way of considering these results, racial/ethnic heterogeneity within neighborhoods increases crime the most when it occurs in cities with low levels of overall racial/ethnic heterogeneity. And whereas segregation has no effect on assault rates when it occurs in cities with average levels of heterogeneity, it has a strong positive effect on assault rates in cities with high levels of racial/ethnic mixing. Thus, whereas racial/ethnic heterogeneity in the city overall increases the aggravated assault rate, this effect is greatly accentuated when it occurs within the context of a city with high levels of segregation. In contrast, racial/ethnic mixing within neighborhoods seems to be least deleterious in cities with a great amount of mixing overall of racial/ethnic groups.

$<<<$ Figure 9 about here $>>>$

The pattern is very similar for robbery rates, as illustrated in Figure 10. Thus, in cities with low overall levels of racial/ethnic heterogeneity, segregation reduces robbery rates. This implies that in such cities, greater levels of neighborhood heterogeneity increase crime rates, leading to higher overall robbery rates compared to other low heterogeneity cities. On the other hand, segregation increases robbery rates in cities with very high levels of heterogeneity. In fact, in cities with high levels of heterogeneity, the degree of segregation is crucial: a city with high heterogeneity in which the neighborhoods tend to be quite mixed will have the lowest robbery rates, whereas a city with high heterogeneity along with high levels of segregation will actually have the highest robbery rates.

$<<<$ Figure 10 about here $>>>$

Turning to the property crimes of burglary and motor vehicle theft rates, the pattern of results is similar. We see in Figure 11 that the level of segregation has very little effect on the 
burglary rate in cities with low levels of heterogeneity. However, in cities with average or high levels of heterogeneity, increasing levels of segregation result in increasing rates of burglaries. The pattern is similar for motor vehicle thefts in Figure 12, with the only exception being that the effect of segregation actually reverses sign in cities with low levels of heterogeneity.

Nonetheless, for both burglaries and motor vehicle thefts, cities with high levels of heterogeneity accompanied by high levels of segregation have the highest rates of each of these crime types. Furthermore, each of these crime types can be ameliorated considerably in high heterogeneity cities if there is a high degree of ethnic mixing within the neighborhoods of these cities.

$<<<$ Figures 11 and 12 about here $>>>$

Finally, although we tested for the same interaction effects in our dynamic equations, we did not find significant effects in any of the models testing the moderating effect of income inequality on economic segregation. For the models testing the moderating effect of racial/ethnic heterogeneity on segregation, just two of the four models showed significant effects.

Furthermore, these results were quite different. For the dynamic model of aggravated assault rates, we see in Figure 13 that whereas increasing segregation always results in falling assault rates over the decade, this negative effect is particularly pronounced in cities undergoing high levels of ethnic churning. Stated differently, the cities experiencing the greatest increases in assault rates are those undergoing large levels of churning, but that churning is bringing together members of different racial/ethnic groups (and therefore reducing segregation—see the right hand side of this figure). This is consistent with prior research in the defended neighborhoods tradition arguing that such inflows of different racial/ethnic group members can lead to a violent response of the part of the residents currently living in the neighborhood (Green, Strolovitch, and Wong 1998; Hipp, Tita, and Boggess 2009). 
The pattern is very different for the property crime type of motor vehicle theft. As seen on the left hand side of Figure 14, cities with small amounts of racial/ethnic churning that is leading to increasing levels of segregation actually have the smallest increases (or even decreases) in motor vehicle theft rates. On the other hand, whereas cities with the greatest levels of racial/ethnic churning experience the largest increases in motor vehicle theft rates, this increase is most pronounced in cities in which segregation is increasing. Thus, these results are considerably different than those for aggravated assault.

$$
<<<\text { Figure } 14 \text { about here }>>>
$$

\section{Conclusion}

In conclusion, this study has shown the importance of simultaneously considering both the micro and the macro social context when understanding crime rates across cities. We have demonstrated that it is not enough to simply focus on neighborhoods within a particular city. Likewise, we have shown that scholars cannot simply create ecological measures at the level of the city when assessing across-city crime comparisons. Instead, it is necessary to focus on both simultaneously in understanding the amount of crime across cities. Although the spatial distribution of certain social characteristics has important consequences for how crime is distributed across the neighborhoods of a city, it is also the case that the distribution of certain social characteristics also affects the total amount of crime in cities. That is, these social phenomena are not simply moving crime about the neighborhoods of a city, but having an impact on the overall amount of crime in the city.

We have shown that the combination of the overall social characteristics of the city and how those social characteristics are distributed across the neighborhoods of a city have important consequences for two dimensions: the economic resources and the racial/ethnic composition of the city. First, we found that the overall level of racial/ethnic mixing (heterogeneity) of the city 
affects the amount of crime. This finding is consistent with prior research. We also found that high levels of racial/ethnic segregation in a city — that is, the spatial distribution of the racial/ethnic groups across the neighborhoods of the city-has important effects. Most importantly, this study was the first to show that there are important interactions between racial/ethnic heterogeneity and segregation. That is, whereas the consistent findings of the neighborhoods and crime literature that racial/ethnic heterogeneity leads to more crime would imply that segregation should actually reduce the amount of crime (since it reduces heterogeneity within the neighborhoods of the city), this was not the case. In fact, this segregation had extremely different effects depending on whether it occurred within the context of a city with a high level of racial/ethnic mixing or a relatively homogeneous city. In cities with high levels of racial/ethnic heterogeneity, segregation results in higher overall levels of crime. Why this occurs is not entirely clear, and suggests an important avenue of future research. We have suggested here that one possible explanation is that in cities with high levels of racial/ethnic mixing, race becomes salient and therefore is particularly notable when it results in segregation of groups into separate neighborhoods. We have suggested that a consequence may be more walled-off neighborhoods, which may lead to higher levels of crime in the city overall. Nonetheless, research explicitly focused on a few of these cities exhibiting this effect would be a useful future direction for research to take.

Second, we found analogous effects for the distribution of economic resources within the city as a whole, as well as how they are spatially distributed across the neighborhoods of cities. We found that cities with overall high levels of inequality have higher levels of all types of crime, which is consistent with prior research. However, whereas some prior research has found that neighborhoods with higher levels of inequality have higher levels of crime, we found that cities with more economic segregation have higher levels of crime. This is surprising given that 
cities with high levels of economic segregation in fact have neighborhoods with low levels of inequality, which should lead to lower crime rates within those neighborhoods which would then aggregate up to lower crime rates for the city as a whole. Again, however, we found an important interaction which has never before been detected in the literature: cities with high inequality and high levels of segregation lead to higher overall rates of crime. Again, we cannot say why this occurs. We have hypothesized that the high level of inequality in such cities makes economic differences particularly salient to residents, which may lead to a perception of walledoff neighborhoods with strikingly different economic resources. One possible scenario would be one in which these defended neighborhoods, in their attempt to protect themselves from crime rates, become more disconnected from adjacent neighborhoods, leading to a higher overall rate of crime. Does this foster more across-neighborhood crime? Clearly, future research will need to drill down to smaller units to assess what process is at work here. We also found that inequality within neighborhoods appears to increase crime the most when it occurs in cities with overall low levels of inequality. Our hypothesis was that this may occur because although inequality is less salient in such cities—leading to a weaker macro effect of inequality on crime across the city proper - that the social differences fostered by inequality within neighborhoods as postulated by social distance theory may have particularly strong effects on increasing crime rates in such cities.

These are paradoxical findings that are unique in the literature and demand the need for new theorizing. Exactly why do we observe such patterns? We have suggested that racial/ethnic differences and economic differences become most salient in cities within which these differences are the greatest. In such instances, we have suggested that these may lead to awareness of differences across neighborhoods, which may lead to increasing crime rates. Clearly, this is of necessity speculative given our inability to measure the actual processes within 
neighborhoods. Nonetheless, the pattern of results is particularly intriguing, and suggests that future research will want to test these findings using multilevel data of neighborhoods nested within cities.

We acknowledge some limitations to our study. First, as just mentioned, we were unable to actually test these processes within neighborhood-level data. Ideally, testing these hypotheses with multilevel data of neighborhoods nested within multiple cities would be ideal. Of course, obtaining such nested data is extremely hard to come by for a sample of cities, nonetheless, this will be necessary to more carefully explore the implications of these findings. Second, our sample of cities focused on cities that have grown in the post World War II era. An advantage of our approach was capturing cities that experienced population growth during the same time period. However, a limitation is that we cannot be certain that these important contextual effects of inequality and heterogeneity will indeed be present in samples of other more stable cities. Future research will be necessary to assess whether this is indeed the case. Third, beyond measuring these characteristics at neighborhoods, it would also be preferable to actually measure the mechanisms hypothesized to bring about these effects. Again, data limitations make measuring such processes particularly challenging. Nonetheless, the pattern of results we have detected suggest that future research attempting to measure such mechanisms in a smaller sample of areas might be fruitful.

In conclusion, the findings of this report suggest the need for both a broader, as well as a narrower, lens. It is not enough for researchers to simply focus on what explains the distribution of crime across the spatial landscape of a city. Although such studies are clearly useful in understanding why some neighborhoods have higher crime rates than others, it is important to be able to distinguish between instances in which the spatial distribution of certain characteristics affects the distribution of crime — that is, act as crime attractors - and other instances in which 
they actually affect the overall amount of crime in the city-that is, act as crime generators. It appears that the overall level of inequality and overall level of racial/ethnic heterogeneity in cities turn these into salient dimensions for citizens. In these instances, isolating citizens into neighborhoods based on their race or economic resources appears to have the most explosive effect on the overall level of crime. 


\section{References}

Agnew, Robert. 1985. "A Revised Strain Theory of Delinquency." Social Forces 64:151-167. - . 1999. "A General Strain Theory of Community Differences in Crime Rates." Journal of Research in Crime and Delinquency 36:123-155.

Aigner, Dennis J. and Arthur S. Goldberger. 1970. "Estimation of Pareto's Law from Grouped Observations." Journal of the American Statistical Association 65:712-723.

Anselin, Luc. 2002. "Under the Hood. Issues in the Specification and Interpretation of Spatial Regression Models." Agricultural Economics 27:247-267.

Bainbridge, William Sims. 1989. "The Religious Ecology of Deviance." American Sociological Review 54:288-295.

Bauer, Daniel J. 2003. "Estimating multilevel linear models as structural equation models." Journal of Educational and Behavioral Statistics 28:135-167.

Bauer, Daniel J. and Patrick J. Curran. 2003. "Distributional Assumptions of Growth Mixture Models: Implications for Over-extraction of Latent Trajectory Classes." Psychological Methods 8:338-363.

—. 2004. "The Integration of Continuous and Discrete Latent Variable Models: Potential Problems and Promising Opportunities." Psychological Methods 9:3-29.

Baumer, Eric, Janet L. Lauritsen, Richard Rosenfeld, and Richard Wright. 1998. "The Influence of Crack Cocaine on Robbery, Burglary, and Homicide Rates: A Cross-City, Longitudinal Analysis." Journal of Research in Crime and Delinquency 35:316-340.

Bellair, Paul E. 1997. "Social Interaction and Community Crime: Examining the Importance of Neighbor Networks." Criminology 35:677-703.

Beyerlein, Kraig and John R. Hipp. 2005. "Social Capital, Too Much of a Good Thing? American Religious Traditions and Community Crime." Social Forces 84:995-1013.

Blau, Judith R. and Peter M. Blau. 1982. "The Cost of Inequality: Metropolitan Structure and Violent Crime." American Sociological Review 47:114-129.

Bollen, Kenneth A., Sharon L. Christ, and John R. Hipp. 2003. "Growth Curve Models." Pp. G35-G38 in Encyclopedia of Social Science Research Methods, edited by M. LewisBeck, A. Bryan, and T. F. Liao. Thousand Oaks, CA: Sage.

Bollen, Kenneth A. and Patrick J. Curran. 2006. Latent Curve Models: A Structural Equation Perspective. New York: John Wiley \& Sons.

Bollen, Kenneth A. and Robert W. Jackman. 1985. "Political Democracy and the Size Distribution of Income." American Sociological Review 50:438-457.

Chamlin, Mitchell B. and John K. Cochran. 1997. "Social Altruism and Crime." Criminology 35:203-228.

Chou, Chih-Ping, Peter M. Bentler, and Mary Ann Pentz. 1998. "Comparisons of Two Statistical Approaches to Study Growth Curves: The Multilevel Model and the Latent Curve Analysis." Structural Equation Modeling 5:247-266.

Cohen, Lawrence E. and Marcus Felson. 1979. "Social Change and Crime Rate Trends: A Routine Activity Approach." American Sociological Review 44:588-608.

Crutchfield, R., Michael Geerken, and Walter Gove. 1982. "Crime Rates and Social Integration: The Impact of Metropolitan Mobility." Criminology 20:467-478.

Crutchfield, Robert D. 1989. "Labor Stratification and Violent Crime." Social Forces 68:489512.

Curran, Patrick J. 2003. "Have multilevel models been structural equation models all along?" Multivariate Behavioral Research 38:529-569. 
Gibbs, Jack P. and Maynard L. Erickson. 1976. "Crime Rates of American Cities in an Ecological Context." American Journal of Sociology 82:605-620.

Gibbs, Jack P. and Walter T. Martin. 1962. "Urbanization, Technology, and the Division of Labor: International Patterns." American Sociological Review 27:667-677.

Golden, Reid M. and Steven F. Messner. 1987. "Dimensions of Racial Inequality and Rates of Violent Crime." Criminology 25:525-541.

Green, Donald P., Dara Z. Strolovitch, and Janelle S. Wong. 1998. "Defended Neighborhoods, Integration, and Racially Motivated Crime." American Journal of Sociology 104:372403.

Guo, Guang and John R. Hipp. 2004. "Analysis of Linear Longitudinal Data." Pp. 347-368 in New Handbook on Data Analysis, edited by M. A. Hardy. London: Sage.

Hannon, Lance. 2002. "Criminal Opportunity Theory and the Relationship between Poverty and Property Crime." Sociological Spectrum 22:363-381.

Hannon, Lance and Peter Knapp. 2003. "Reassessing Nonlinearity in the Urban

Disadvantage/Violent Crime Relationship: An Example of Methodological Bias from Log Transformation." Criminology 41:1427-1448.

Harding, David J. 2007. "Cultural Context, Sexual Behavior, and Romantic Relationships in Disadvantaged Neighborhoods." American Sociological Review 72:341-364.

Harer, Miles D. and Darrell Steffensmeier. 1992. "The Differing Effects of Economic Inequality on Black and White Rates of Violence." Social Forces 70:1035-1054.

Hipp, John R. 2007. "Income Inequality, Race, and Place: Does the Distribution of Race and Class within Neighborhoods affect Crime Rates?" Criminology 45:665-697.

Hipp, John R., Daniel J. Bauer, Patrick J. Curran, and Kenneth A. Bollen. 2004. "Crimes of Opportunity or Crimes of Emotion: Testing Two Explanations of Seasonal Change in Crime." Social Forces 82:1333-1372.

Hipp, John R. and Andrew J. Perrin. 2009. "The Simultaneous Effect of Social Distance and Physical Distance on the Formation of Neighborhood Ties." City \& Community 8:5-25.

Hipp, John R., George E. Tita, and Lyndsay N. Boggess. 2009. "Inter- and Intra-group violence: Is violent crime an expression of group conflict or social disorganization?" Criminology 47:521-564.

Hunter, Albert. 1995. "Private, Parochial and Public Social Orders: The Problem of Crime and Incivility in Urban Communities." Pp. 204-225 in Metropolis: Center and Symbol of Our Times, edited by P. Kasinitz. New York: New York University.

Jasso, Guillermina. 1980. "A New Theory of Distributive Justice." American Sociological Review 45:3-32.

Kakwani, N. C. and N. Podder. 1976. "Efficient Estimation of the Lorenz Curve and Associated Inequality Measures From Grouped Observations." Econometrica 44:137-148.

Kawachi, Ichiro, Bruce P Kennedy, Kimberly Lochner, and Deborah Prothrow-Stith. 1997. "Social Capital, Income Inequality, and Mortality." American Journal of Public Health 87:1491-1498.

Kovandzic, Tomislav V., Lynne M. Vieratis, and Mark R. Yeisley. 1998. "The Structural Covariates of Urban Homicide: Reassessing the Impact of Income Inequality and Poverty in the Post-Reagan Era." Criminology 36:569-599.

Kposowa, Augustine J., Kevin D. Breault, and Beatrice M. Harrison. 1995. "Reassessing the Structural Covariates of Violent and Property Crimes in the USA: A County Level Analysis." British Journal of Sociology 46:79-105.

Krivo, Lauren J. and Ruth D. Peterson. 1996. "Extremely Disadvantaged Neighborhoods and Urban Crime." Social Forces 75:619-648. 
Land, Kenneth C., Patricia L. McCall, and Lawrence E. Cohen. 1990. "Structural Covariates of Homicide Rates: Are There Any Invariances across Time and Social Space?" American Journal of Sociology 95:922-963.

Lang, Robert and Patrick Simmons. 2001. "Boomburbs: The Emergence of Large, Fast-Growing Suburban Cities in the United States." in Fannie Mae Foundation Census Note 06.

Lee, Matthew R. and Graham C. Ousey. 2007. "Counterbalancing Disadvantage? Residential Integration and Urban Black Homicide." Social Problems 54:240-262.

Lee, Sik-Yum and Sin-Yu Tsang. 1999. "Constrained Maximum Likelihood Estimation of TwoLevel Covariance Structure Model via EM Type Algorithms." Psychometrika 64:435450.

Liska, Allen E. and Paul E. Bellair. 1995. "Violent-Crime Rates and Racial Composition: Convergence Over Time." American Journal of Sociology 101:578-610.

Liska, Allen E., John R. Logan, and Paul E. Bellair. 1998. "Race and Violent Crime in the Suburbs." American Sociological Review 63:27-38.

Lowenkamp, Christopher T., Francis T. Cullen, and Travis C. Pratt. 2003. "Replicating Sampson and Groves's Test of Social Disorganization Theory: Revisiting a Criminological Classic." Journal of Reserach in Crime and Delinquency 40:351-373.

MacCallum, Robert C., Cheongtag Kim, William B. Malarkey, and Janice K. Kiecolt-Glaser. 1997. "Studying Multivariate Change Using Multilevel Models and Latent Curve Models." Multivariate Behavioral Research 32:215-253.

McClain, Paula D. 1989. "Urban Black Neighborhood Environment and Homicide: A Research Note on a Decade of Change in Four Cities--1970 to 1980." Urban Affairs Quarterly 24:584-596.

McPherson, Miller, Lynn Smith-Lovin, and James M Cook. 2001. "Birds of a Feather: Homophily in Social Networks." Annual Review of Sociology 27:415-444.

McVeigh, Rory. 2006. "Structural Influences on Activism and Crime: Identifying the Social Structure of Discontent." American Journal of Sociology 112:510-566.

Mehta, Paras D. and Stephen G. West. 2000. "Putting the Individual Back Into Individual Growth Curves." Psychological Methods 5:23-43.

Messner, Steven F. 1983a. "Regional and Racial Effects on the Urban Homicide Rate: The Subculture of Violence Revisited." American Journal of Sociology 88:997-1007.

—. 1983b. "Regional Differences in the Economic Correlates of the Urban Homicide Rate." Criminology 21:477-488.

Messner, Steven F. and Judith R. Blau. 1987. "Routine Leisure Activities and Rates of Crime: A Macro-Level Analysis." Social Forces 65:1035-1052.

Messner, Steven F. and Kenneth Tardiff. 1986. "Economic Inequality and Levels of Homicide: An Analysis of Urban Neighborhoods." Criminology 24:297-317.

Miethe, Terance D., Michael Hughes, and David McDowall. 1991. "Social Change and Crime Rates: An Evaluation of Alternative Theoretical Approaches." Social Forces 70:165-185.

Nielsen, Francois and Arthur S. Alderson. 1997. "The Kuznets Curve and the Great U-Turn: Income Inequality in U.S. Counties, 1970 to 1990." American Sociological Review 62:1233.

Ouimet, Marc. 2000. "Aggregation Bias in Ecological Research: How Social Disorganization and Criminal Opportunities Shape the Spatial Distribution of Juvenile Delinquency in Montreal." Canadian Journal of Criminology 42:135-156.

Ousey, Graham C. 1999. "Homicide, Structural Factors, and the Racial Invariance Assumption." Criminology 37:405-426. 
Pastor, Manuel Jr., Jim Sadd, and John Hipp. 2001. "Which Came First? Toxic Facilities, Minority Move-in, and Environmental Justice." Journal of Urban Affairs 23:1-21.

Peterson, Ruth D., Lauren J. Krivo, and Mark A. Harris. 2000. "Disadvantage and Neighborhood Violent Crime: Do Local Institutions Matter?" Journal of Research in Crime and Delinquency 37:31-63.

Putnam, Robert D. 1995. "Bowling Alone: America's Declining Social Capital." Journal of Democracy 6:65-78.

- 2000. Bowling Alone: The Collapse and Revival of American Community. New York: Simon \& Schuster.

Raudenbush, Stephen W. 2001. "Toward a Coherent Framework for Comparing Trajectories of Individual Change." Pp. 35-64 in New Methods for the Analysis of Change, Decade of Behavior: 2000-2010, edited by L. M. Collins and A. G. Sayer. Washington, D.C.: American Psychological Association.

Roncek, Dennis W. 1981. "Dangerous Places: Crime and Residential Environment." Social Forces 60:74-96.

Roncek, Dennis W. and Pamela A. Maier. 1991. "Bars, Blocks, and Crimes Revisited: Linking the Theory of Routine Activities to the Empiricism of 'Hot Spots'." Criminology 29:725753.

Rueschemeyer, Dietrich, Evelyne Huber Stephens, and John D. Stephens. 1992. Capitalist Development \& Democracy. Chicago: University of Chicago.

Sampson, Robert J. 1985. "A Demographically Disaggregated Analysis of Urban Homicide." Crime and Delinquency 31:47-82.

—. 1987. "Urban Black Violence: The Effect of Male Joblessness and Family Disruption." American Journal of Sociology 93:348-382.

Sampson, Robert J. and W. Byron Groves. 1989. "Community Structure and Crime: Testing Social-Disorganization Theory." American Journal of Sociology 94:774-802.

Sampson, Robert J. and William Julius Wilson. 1995. "Toward a Theory of Race, Crime, and Urban Inequality." Pp. 37-54 in Crime and Inequality, edited by J. Hagan and R. D. Peterson. Stanford, CA: Stanford University Press.

Shaw, Clifford and Henry D. McKay. 1942. Juvenile Delinquency and Urban Areas. Chicago: University of Chicago Press.

Shihadeh, Edward S. and Nicole Flynn. 1996. "Segregation and Crime: The Effect of Black Social Isolation on the Rates of Black Urban Violence." Social Forces 74:1325-1352.

Shihadeh, Edward S. and Graham C. Ousey. 1996. "Metropolitan Expansion and Black Social Dislocation: The Link Between Suburbanization and Center-City Crime." Social Forces 75:649-666.

Simpson, Miles E. 1985. "Violent Crime, Income Inequality, and Regional Culture: Another Look." Sociological Focus 18:199-208.

Suttles, Gerald D. 1972. The Social Construction of Communities. Chicago: University of Chicago.

Theil, Henry. 1967. Economics and Information Theory, vol. 7. Chicago: Rand McNally.

Tolbert, Charles M, Thomas A Lyson, and Michael D Irwin. 1998. "Local capitalism, civic engagement, and socioeconomic well-being." Social Forces 77:401-427.

Veysey, Bonita M. and Steven F. Messner. 1999. "Further Testing of Social Disorganization Theory: An Elaboration of Sampson and Groves's 'Community Structure and Crime'." Journal of Research in Crime and Delinquency 36:156-174.

Warner, Barbara D. and Glenn L. Pierce. 1993. "Reexamining Social Disorganization Theory Using Calls to the Police as a Measure of Crime." Criminology 31:493-517. 
Warner, Barbara D. and Pamela Wilcox Rountree. 1997. "Local Social Ties in a Community and Crime Model: Questioning the Systemic Nature of Informal Social Control." Social Problems 44:520-536.

Wilkinson, Richard G. 1996. Unhealthy Societies: The Afflications of Inequality. New York: Routledge.

Williams, Kirk R. 1984. "Economic Sources of Homicide: Reestimating the Effects of Poverty and Inequality." American Sociological Review 49:283-289.

Williams, Kirk R. and Robert L. Flewelling. 1988. "The Social Production of Criminal Homicide: A Comparative Study of Disaggregated Rates in American Cities." American Sociological Review 53:421-431.

Wilson, William J. 1987. The Truly Disadvantaged: The Inner City, the Underclass, and Public Policy. Chicago: University of Chicago Press.

Wolfgang, Marvin E. and Franco Ferracuti. 1967. The subculture of violence: Towards an integrated theory in criminology. London: Tavistock. 


\section{Tables and Figures}

Table 1. Summary statistics for variables used in analyses

\begin{tabular}{|c|c|c|c|c|c|c|}
\hline & \multicolumn{2}{|c|}{1970} & \multicolumn{2}{|c|}{1980} & \multicolumn{2}{|c|}{1990} \\
\hline & Mean & Std Dev & Mean & Std Dev & Mean & Std Dev \\
\hline Age of buildings & 13.39 & 4.62 & 16.00 & 6.02 & 17.59 & 7.76 \\
\hline Percent owners & 66.15 & 17.93 & 73.36 & 16.81 & 68.62 & 17.99 \\
\hline Percent single parent households & 6.51 & 2.87 & 14.02 & 8.49 & 16.15 & 9.96 \\
\hline Percent occupied units & 93.51 & 6.25 & 90.03 & 10.21 & 87.30 & 11.64 \\
\hline Unemployment rate & 4.12 & 1.84 & 4.66 & 3.01 & 5.63 & 3.36 \\
\hline Average family income & 11,861 & 3,733 & 26,333 & 12,683 & 51,971 & 31,977 \\
\hline Racial/e thnic heterogeneity & 20.07 & 15.56 & 23.22 & 17.24 & 30.21 & 18.45 \\
\hline Percent black & 5.82 & 13.76 & 6.43 & 15.21 & 8.01 & 16.35 \\
\hline Percent Latino & 7.45 & 9.51 & 9.77 & 12.81 & 13.91 & 15.85 \\
\hline Percent enrolled in college & 17.75 & 12.37 & 25.61 & 17.34 & 40.17 & 20.39 \\
\hline Percent crowded households & 3.53 & 2.20 & 5.81 & 6.25 & 6.20 & 6.78 \\
\hline \multirow[t]{2}{*}{ Population } & 31,625 & 81,032 & 24,613 & 72,308 & 28,204 & 81,635 \\
\hline & & & & & 2,616 & 2,319 \\
\hline Racial/ethnic segregation & 0.17 & 0.19 & 0.05 & 0.11 & -0.19 & 0.13 \\
\hline Income segregation & 0.22 & 0.17 & 0.20 & 0.13 & 0.20 & 0.14 \\
\hline Income inequality & 33.26 & 5.66 & 33.64 & 6.26 & 35.01 & 6.01 \\
\hline
\end{tabular}

$N=352$ cities 
This document is a research report submitted to the U.S. Department of Justice. This report has not

been published by the Department. Opinions or points of view expressed are those of the author(s)

and do not necessarily reflect the official position or policies of the U.S. Department of Justice.

Table 2. Predicting various types of crime. Boomburb cities from 1970-2000

\begin{tabular}{|c|c|c|c|c|c|c|c|c|}
\hline & \multicolumn{2}{|c|}{ Aggravated assault rate } & \multicolumn{2}{|c|}{ Robbery rate } & \multicolumn{2}{|c|}{ Burglary rate } & \multicolumn{2}{|c|}{ Motor vehicle theft rate } \\
\hline & Intercept & Slope & Intercept & Slope & Intercept & Slope & Intercept & Slope \\
\hline Age of buildings & $\begin{array}{l}0.054 * * \\
(2.64)\end{array}$ & $\begin{array}{l}-0.004 \\
-(1.42)\end{array}$ & $\begin{array}{l}-0.001 \\
-(0.14)\end{array}$ & $\begin{array}{l}-0.002 \dagger \\
-(1.84)\end{array}$ & $\begin{array}{l}0.006 \\
(0.14)\end{array}$ & $\begin{array}{l}-0.012 * \\
-(2.00)\end{array}$ & $\begin{array}{l}-0.023 \\
-(1.31)\end{array}$ & $\begin{array}{l}-0.004 \\
-(1.54)\end{array}$ \\
\hline Percent owners & $\begin{array}{l}-0.014 \\
-(1.45)\end{array}$ & $\begin{array}{r}0.000 \\
-(0.35)\end{array}$ & $\begin{array}{l}-0.006 \dagger \\
-(1.65)\end{array}$ & $\begin{array}{l}-0.001 * \\
-(2.44)\end{array}$ & $\begin{array}{l}-0.030 \\
-(1.35)\end{array}$ & $\begin{array}{l}-0.008 * \\
-(2.41)\end{array}$ & $\begin{array}{l}-0.020 \text { ** } \\
-(2.72)\end{array}$ & $\begin{array}{l}0.001 \\
(0.62)\end{array}$ \\
\hline Percent single parent households & $\begin{array}{l}0.051 * \\
(2.29)\end{array}$ & $\begin{array}{l}-0.004 * * \\
-(2.64)\end{array}$ & $\begin{array}{l}0.020 * \\
(2.53)\end{array}$ & $\begin{array}{l}-0.002 * * \\
-(3.13)\end{array}$ & $\begin{array}{l}0.151 \text { ** } \\
(3.40)\end{array}$ & $\begin{array}{l}-0.010 * * \\
-(2.84)\end{array}$ & $\begin{array}{l}0.050 \text { ** } \\
(3.17)\end{array}$ & $\begin{array}{l}0.000 \\
(0.09)\end{array}$ \\
\hline Percent occupied units & $\begin{array}{l}-0.031 * \\
-(2.26)\end{array}$ & $\begin{array}{l}0.000 \\
(0.33)\end{array}$ & $\begin{array}{l}0.008 \\
(1.47)\end{array}$ & $\begin{array}{r}0.000 \\
-(0.27)\end{array}$ & $\begin{array}{l}-0.177^{* *} \\
-(6.08)\end{array}$ & $\begin{array}{l}0.010 * * \\
(2.71)\end{array}$ & $\begin{array}{l}-0.001 \\
-(0.11)\end{array}$ & $\begin{array}{l}0.003 \dagger \\
(1.80)\end{array}$ \\
\hline Unemployment rate & $\begin{array}{l}0.021 \\
(0.33)\end{array}$ & $\begin{array}{l}-0.002 \\
-(0.52)\end{array}$ & $\begin{array}{l}-0.002 \\
-(0.10)\end{array}$ & $\begin{array}{l}0.001 \\
(0.57)\end{array}$ & $\begin{array}{l}0.193 \\
(1.53)\end{array}$ & $\begin{array}{l}0.035 * * \\
(3.66)\end{array}$ & $\begin{array}{l}-0.060 \\
-(1.40)\end{array}$ & $\begin{array}{l}0.007 \\
(1.62)\end{array}$ \\
\hline Average family income & $\begin{array}{l}-0.495 \\
-(0.76)\end{array}$ & $\begin{array}{l}-0.070 \\
-(1.34)\end{array}$ & $\begin{array}{l}0.012 \\
(0.05)\end{array}$ & $\begin{array}{l}-0.044 * \\
-(2.29)\end{array}$ & $\begin{array}{l}0.622 \\
(0.50)\end{array}$ & $\begin{array}{l}-0.124 \\
-(1.17)\end{array}$ & $\begin{array}{l}-0.780 \\
-(1.36)\end{array}$ & $\begin{array}{l}-0.012 \\
-(0.18)\end{array}$ \\
\hline
\end{tabular}


This document is a research report submitted to the U.S. Department of Justice. This report has not

been published by the Department. Opinions or points of view expressed are those of the author(s)

and do not necessarily reflect the official position or policies of the U.S. Department of Justice.

\begin{tabular}{|c|c|c|c|c|c|c|c|c|c|}
\hline Racial/ethnic heterogeneity & $\begin{array}{l}0.005 \\
(0.47)\end{array}$ & $\begin{array}{l}0.003 * * \\
(2.67)\end{array}$ & $\begin{array}{l}-0.007 \\
-(1.48)\end{array}$ & $\begin{array}{l}0.001 \\
(2.27)\end{array}$ & $*$ & $\begin{array}{l}0.035 \\
(1.52)\end{array}$ & $\begin{array}{l}0.003 \\
(1.14)\end{array}$ & $\begin{array}{l}0.008 \\
(0.87)\end{array}$ & $\begin{array}{l}0.001 \\
(1.02)\end{array}$ \\
\hline Percent black & $\begin{array}{l}0.104 * * \\
(6.69)\end{array}$ & $\begin{array}{l}0.000 \\
(0.02)\end{array}$ & $\begin{array}{l}0.037 * * \\
(5.42)\end{array}$ & $\begin{array}{l}0.002 \\
(2.82)\end{array}$ & $* *$ & $\begin{array}{l}0.069 * \\
(2.03)\end{array}$ & $\begin{array}{l}0.015 * * \\
(3.28)\end{array}$ & $\begin{array}{l}0.005 \\
(0.37)\end{array}$ & $\begin{array}{l}0.003 \\
(1.26)\end{array}$ \\
\hline Percent Latino & $\begin{array}{l}0.001 \\
(0.05)\end{array}$ & $\begin{array}{l}-0.002 \\
-(0.86)\end{array}$ & $\begin{array}{l}0.003 \\
(0.39)\end{array}$ & $\begin{array}{l}0.001 \\
(1.65)\end{array}$ & $\dagger$ & $\begin{array}{l}-0.006 \\
-(0.15)\end{array}$ & $\begin{array}{l}0.005 \\
(1.08)\end{array}$ & $\begin{array}{l}0.034 \text { * } \\
(2.29)\end{array}$ & $\begin{array}{l}0.001 \\
(0.40)\end{array}$ \\
\hline Percent enrolled in college & $\begin{array}{l}-0.037 * * \\
-(4.07)\end{array}$ & $\begin{array}{l}-0.001 \\
-(1.21)\end{array}$ & $\begin{array}{l}0.001 \\
(0.24)\end{array}$ & $\begin{array}{l}0.000 \\
(0.43)\end{array}$ & & $\begin{array}{l}-0.038 \dagger \\
-(1.95)\end{array}$ & $\begin{array}{l}-0.005 * \\
-(2.28)\end{array}$ & $\begin{array}{l}0.002 \\
(0.35)\end{array}$ & $\begin{array}{l}-0.002 \\
-(1.54)\end{array}$ \\
\hline Percent crowded households & $\begin{array}{l}0.044 \\
(1.05)\end{array}$ & $\begin{array}{l}0.004 \\
(1.23)\end{array}$ & $\begin{array}{l}0.035 * \\
(2.27)\end{array}$ & $\begin{array}{l}-0.001 \\
-(1.10)\end{array}$ & & $\begin{array}{l}0.057 \\
(0.67)\end{array}$ & $\begin{array}{l}-0.021 * * \\
-(2.72)\end{array}$ & $\begin{array}{l}0.001 \\
(0.04)\end{array}$ & $\begin{array}{l}-0.002 \\
-(0.66)\end{array}$ \\
\hline Population & $\begin{array}{l}0.008 \\
(0.72)\end{array}$ & $\begin{array}{l}-0.001 \\
-(0.40)\end{array}$ & $\begin{array}{l}0.014 * \\
(2.25)\end{array}$ & $\begin{array}{l}0.002 \\
(2.05)\end{array}$ & $*$ & $\begin{array}{l}-0.015 \\
-(0.57)\end{array}$ & $\begin{array}{l}0.008 \\
(1.40)\end{array}$ & $\begin{array}{l}0.007 \\
(0.54)\end{array}$ & $\begin{array}{l}0.008 \text { * } \\
(2.37)\end{array}$ \\
\hline Income inequality & $\begin{array}{l}0.525 * \\
(2.18)\end{array}$ & $\begin{array}{l}0.006 \text { ** } \\
(2.61)\end{array}$ & $\begin{array}{l}0.278 \text { ** } \\
(2.95)\end{array}$ & $\begin{array}{l}0.001 \\
(1.11)\end{array}$ & & $\begin{array}{l}1.059 \text { * } \\
(1.97)\end{array}$ & $\begin{array}{l}0.000 \\
(0.00)\end{array}$ & $\begin{array}{l}0.190 \\
(0.98)\end{array}$ & $\begin{array}{l}0.012 * * \\
(2.81)\end{array}$ \\
\hline Income inequality squared & $\begin{array}{l}0.148 \\
(1.28)\end{array}$ & & $\begin{array}{l}0.086 \dagger \\
(1.81)\end{array}$ & & & $\begin{array}{l}0.972 \text { ** } \\
(3.71)\end{array}$ & & $\begin{array}{l}0.027 \\
(0.29)\end{array}$ & \\
\hline
\end{tabular}

${ }^{* *} p<.01$ (two-tail test), * $p<.05$ (two-tail test), $\dagger p<.05$ (one-tail test). T-values in parentheses. $N=352$ cities 
This document is a research report submitted to the U.S. Department of Justice. This report has not been published by the Department. Opinions or points of view expressed are those of the author(s) and do not necessarily reflect the official position or policies of the U.S. Department of Justice.

\section{Figure 1}

Figure 1. Aggravated Assault rate at one time point, predicted by racial/ethnic segregation

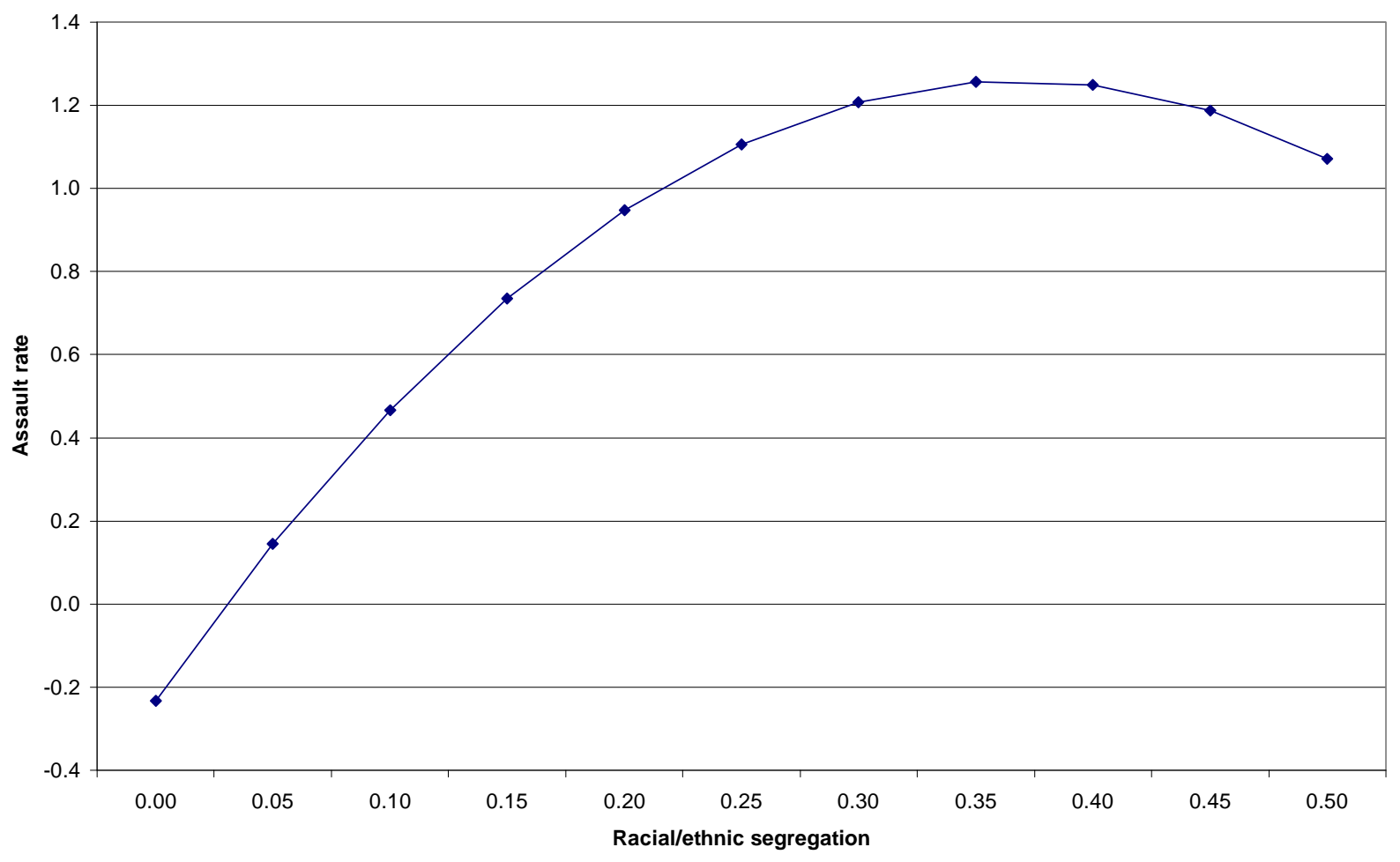


This document is a research report submitted to the U.S. Department of Justice. This report has not been published by the Department. Opinions or points of view expressed are those of the author(s) and do not necessarily reflect the official position or policies of the U.S. Department of Justice.

\section{Figure 2}

Figure 2. Robbery rate at one time point, predicted by inequality

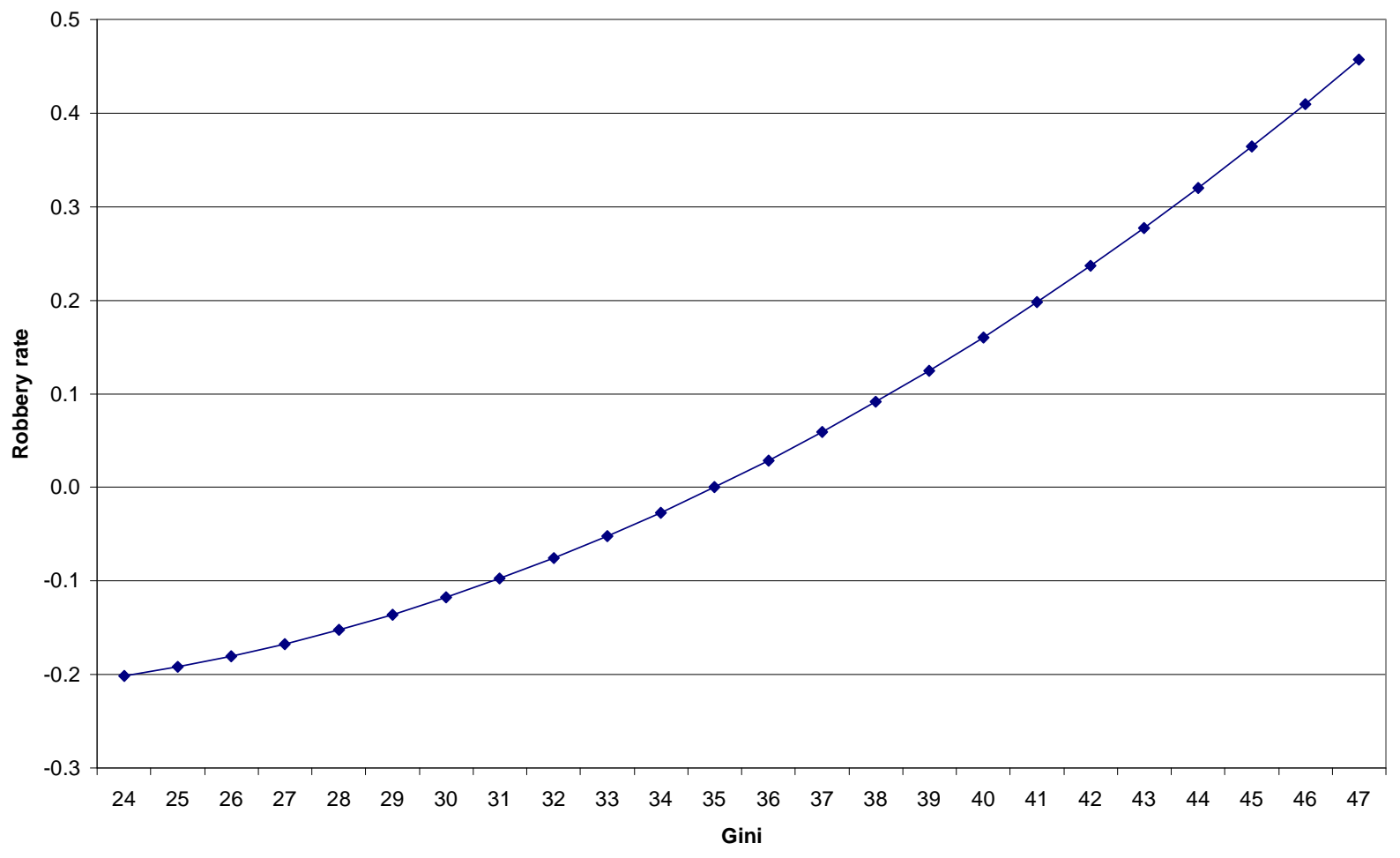


This document is a research report submitted to the U.S. Department of Justice. This report has not been published by the Department. Opinions or points of view expressed are those of the author(s) and do not necessarily reflect the official position or policies of the U.S. Department of Justice.

Figure 3

Figure 3. Burglary rate at one time point, predicted by inequality

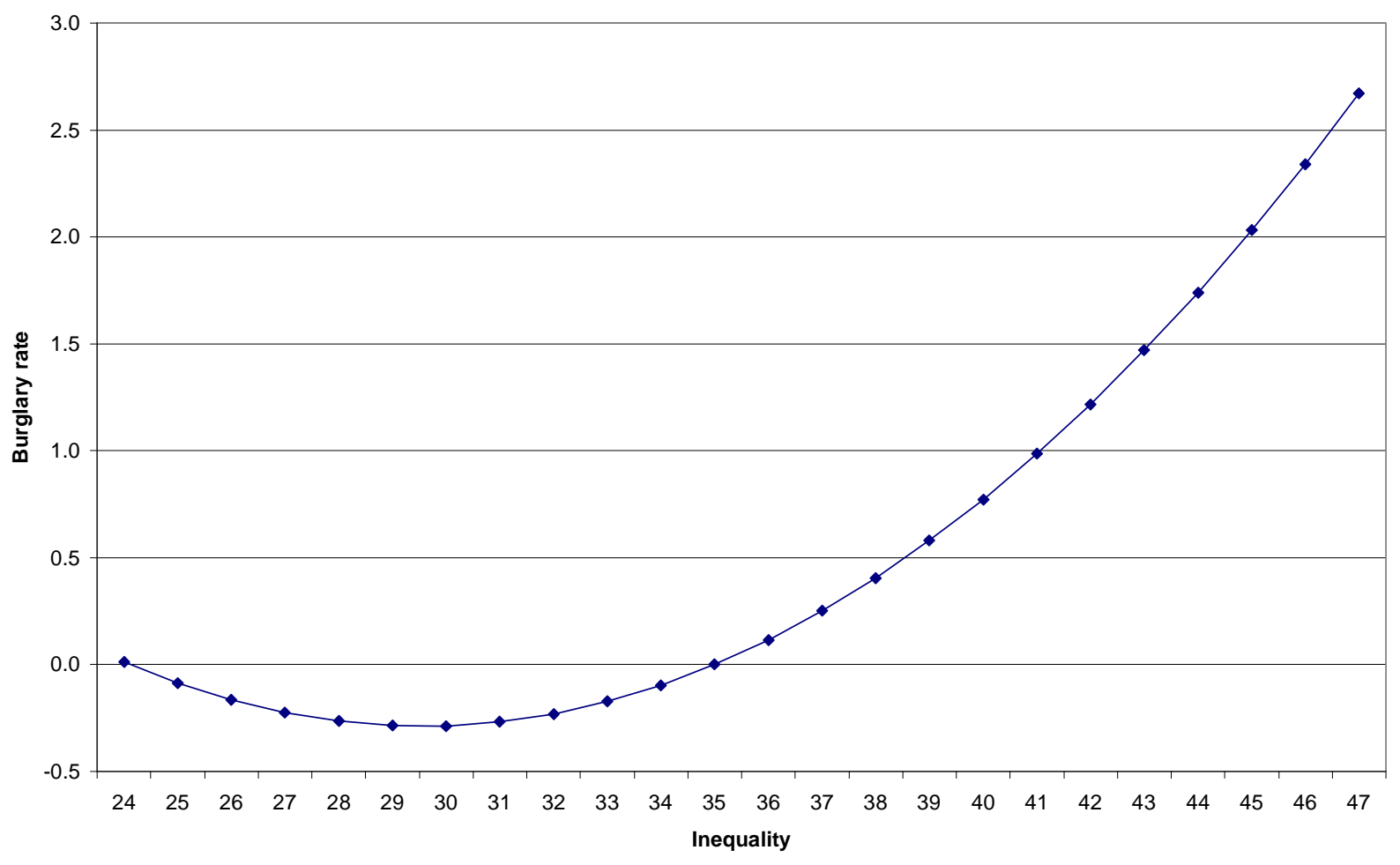


This document is a research report submitted to the U.S. Department of Justice. This report has not been published by the Department. Opinions or points of view expressed are those of the author(s) and do not necessarily reflect the official position or policies of the U.S. Department of Justice.

Figure 4

Figure 4. Burglary rate at one time point, predicted by income segregation

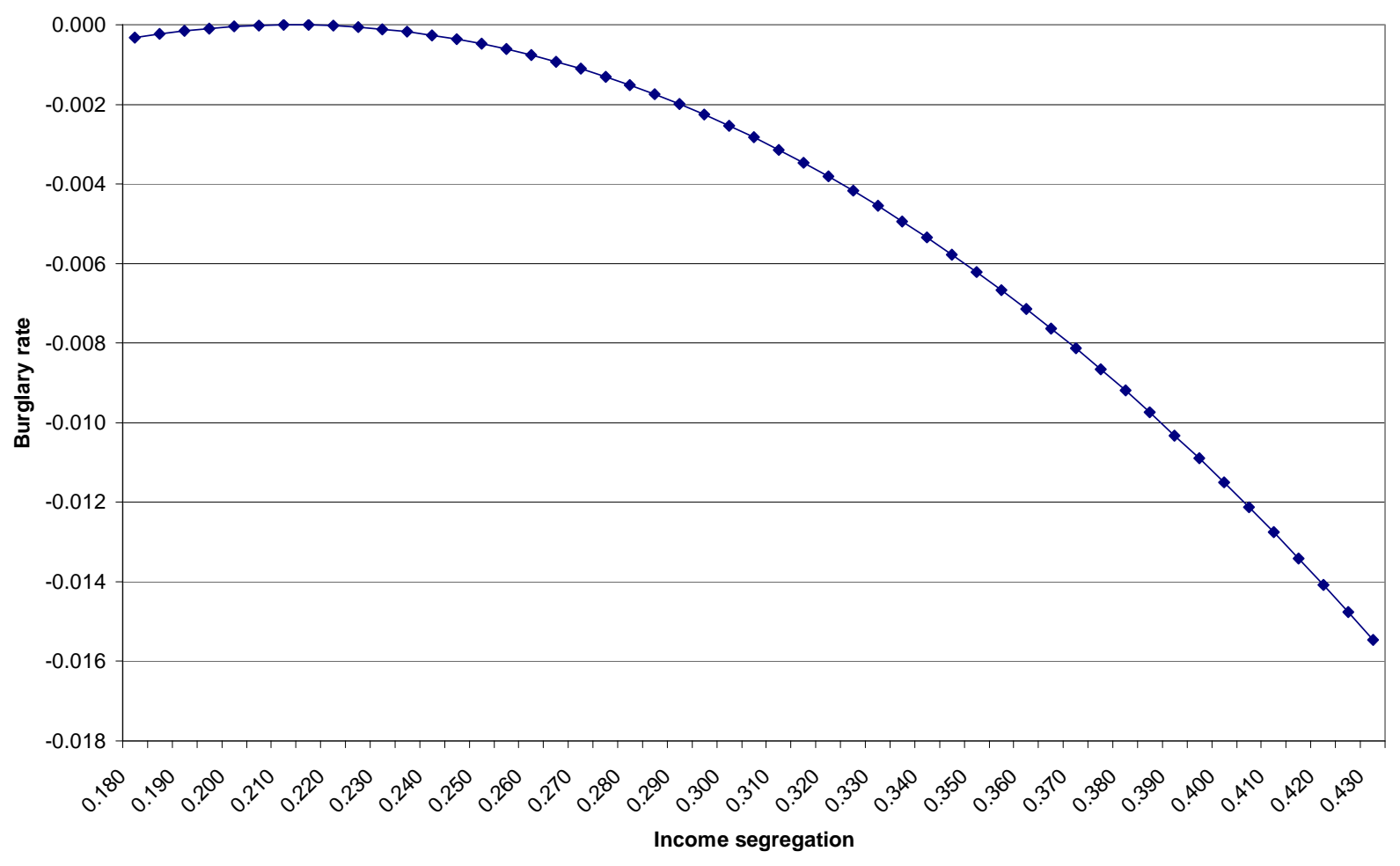


This document is a research report submitted to the U.S. Department of Justice. This report has not been published by the Department. Opinions or points of view expressed are those of the author(s) and do not necessarily reflect the official position or policies of the U.S. Department of Justice.

Figure 5

Figure 5. Aggravated assault predicted by interaction of inequality and economic segregation

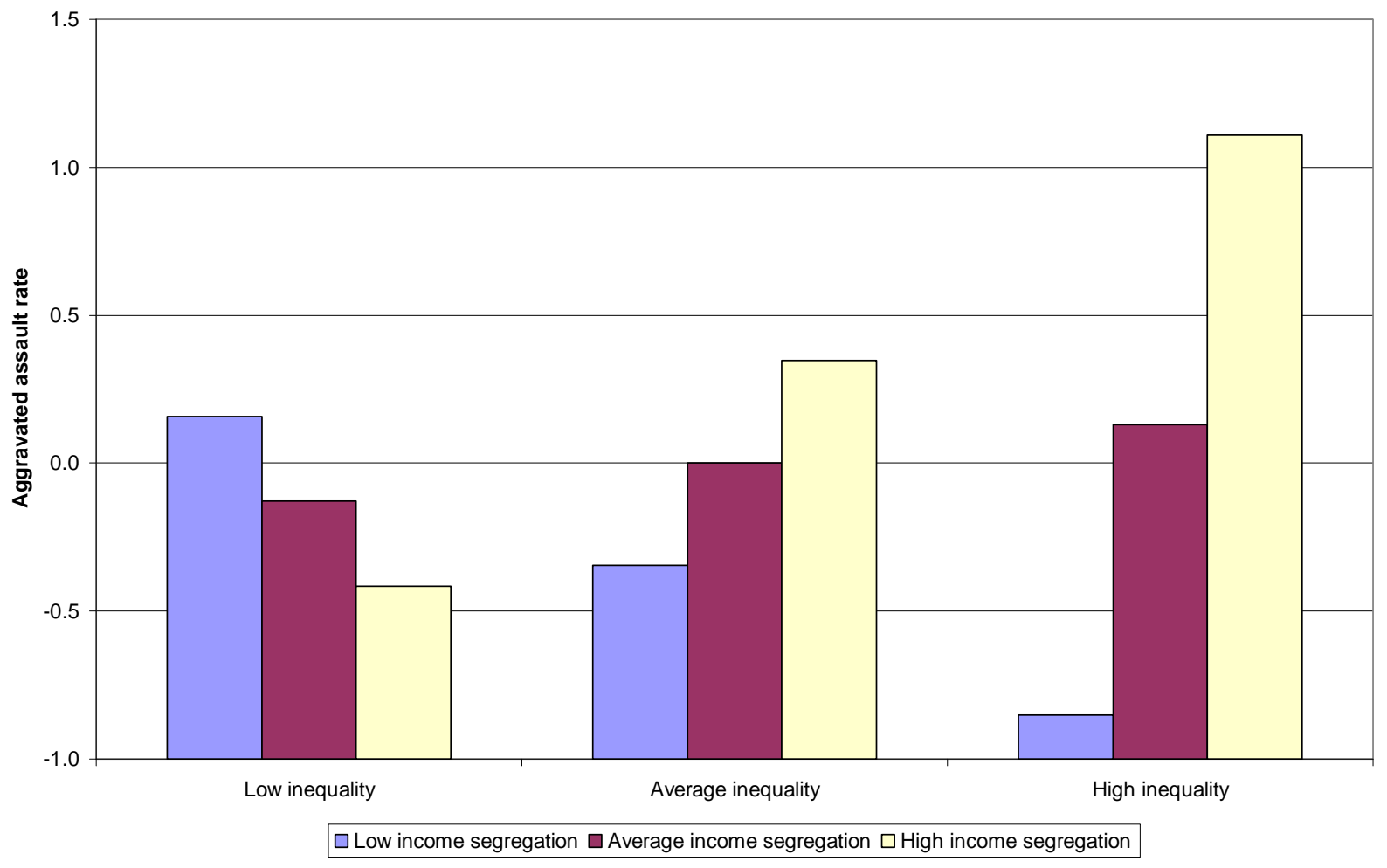


This document is a research report submitted to the U.S. Department of Justice. This report has not been published by the Department. Opinions or points of view expressed are those of the author(s) and do not necessarily reflect the official position or policies of the U.S. Department of Justice.

Figure 6

Figure 6. Robbery rates predicted by interaction of inequality and economic segregation

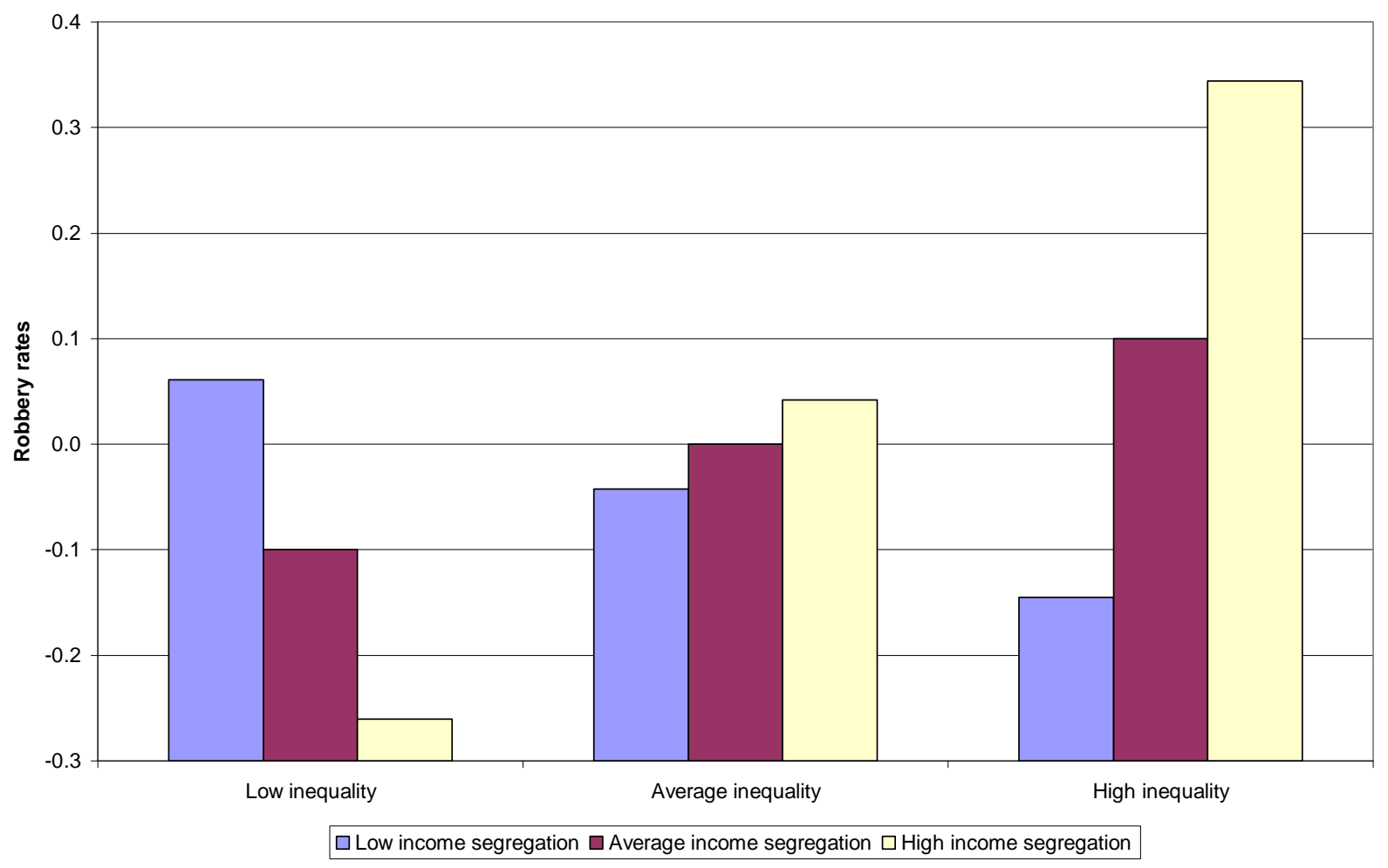


This document is a research report submitted to the U.S. Department of Justice. This report has not been published by the Department. Opinions or points of view expressed are those of the author(s) and do not necessarily reflect the official position or policies of the U.S. Department of Justice.

Figure 7

Figure 7. Burglary rates predicted by interaction of inequality and economic segregation

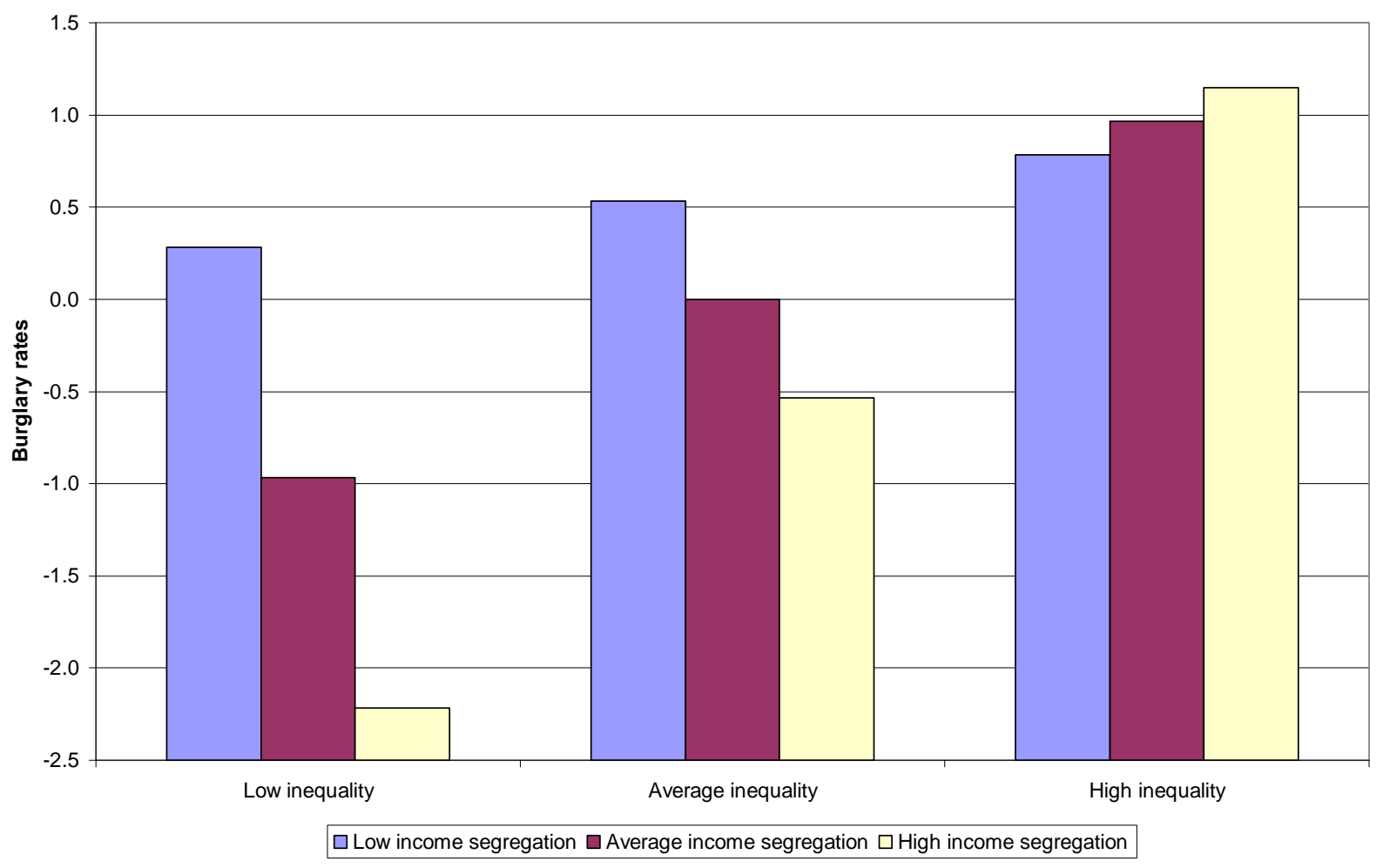


This document is a research report submitted to the U.S. Department of Justice. This report has not been published by the Department. Opinions or points of view expressed are those of the author(s) and do not necessarily reflect the official position or policies of the U.S. Department of Justice.

Figure 8

Figure 8. Motor vehicle theft rates predicted by interaction of inequality and economic segregation

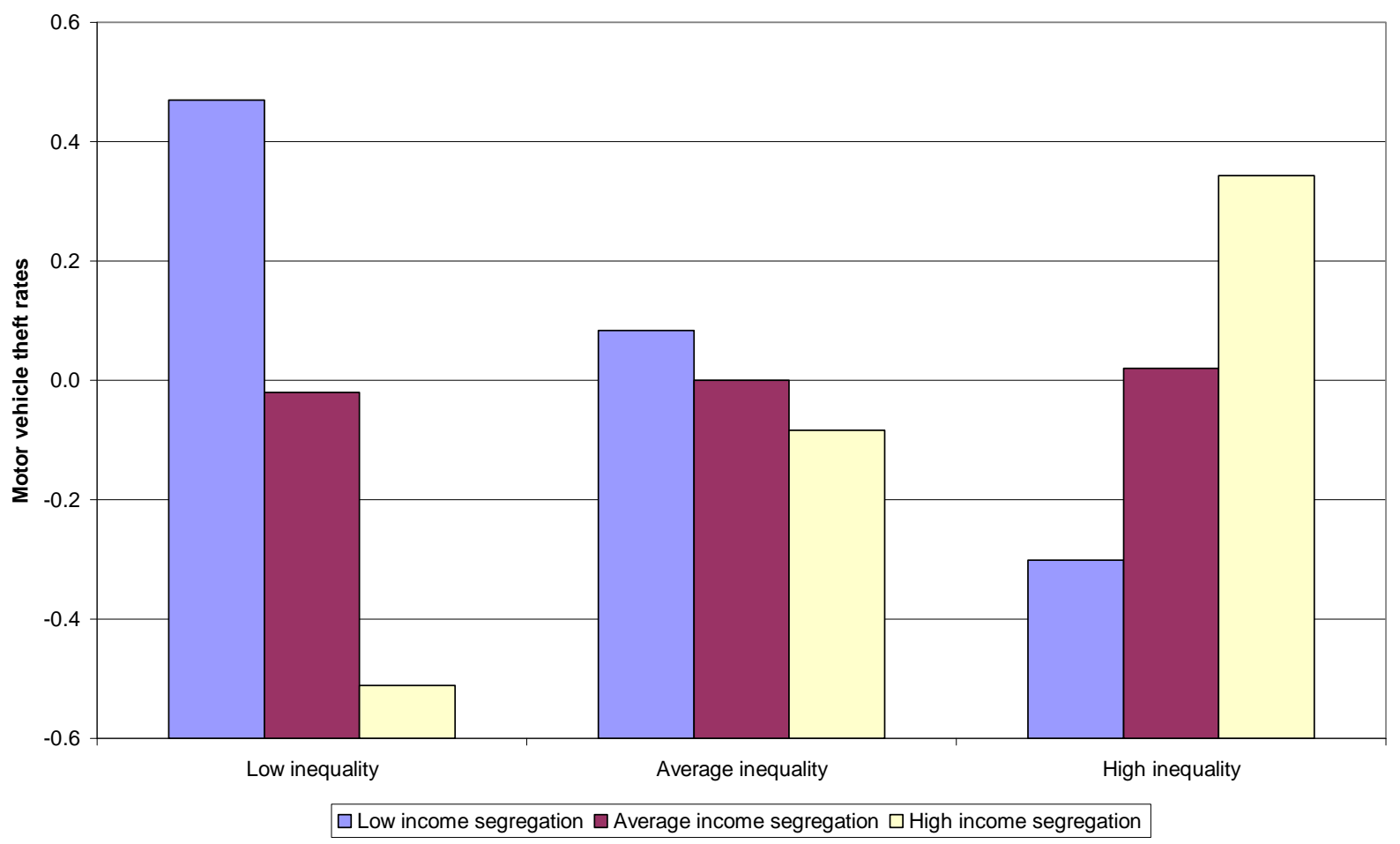


This document is a research report submitted to the U.S. Department of Justice. This report has not been published by the Department. Opinions or points of view expressed are those of the author(s) and do not necessarily reflect the official position or policies of the U.S. Department of Justice.

Figure 9

Figure 9. Aggravated Assault rates predicted by interaction of racial/ethnic heterogeneity and segregation

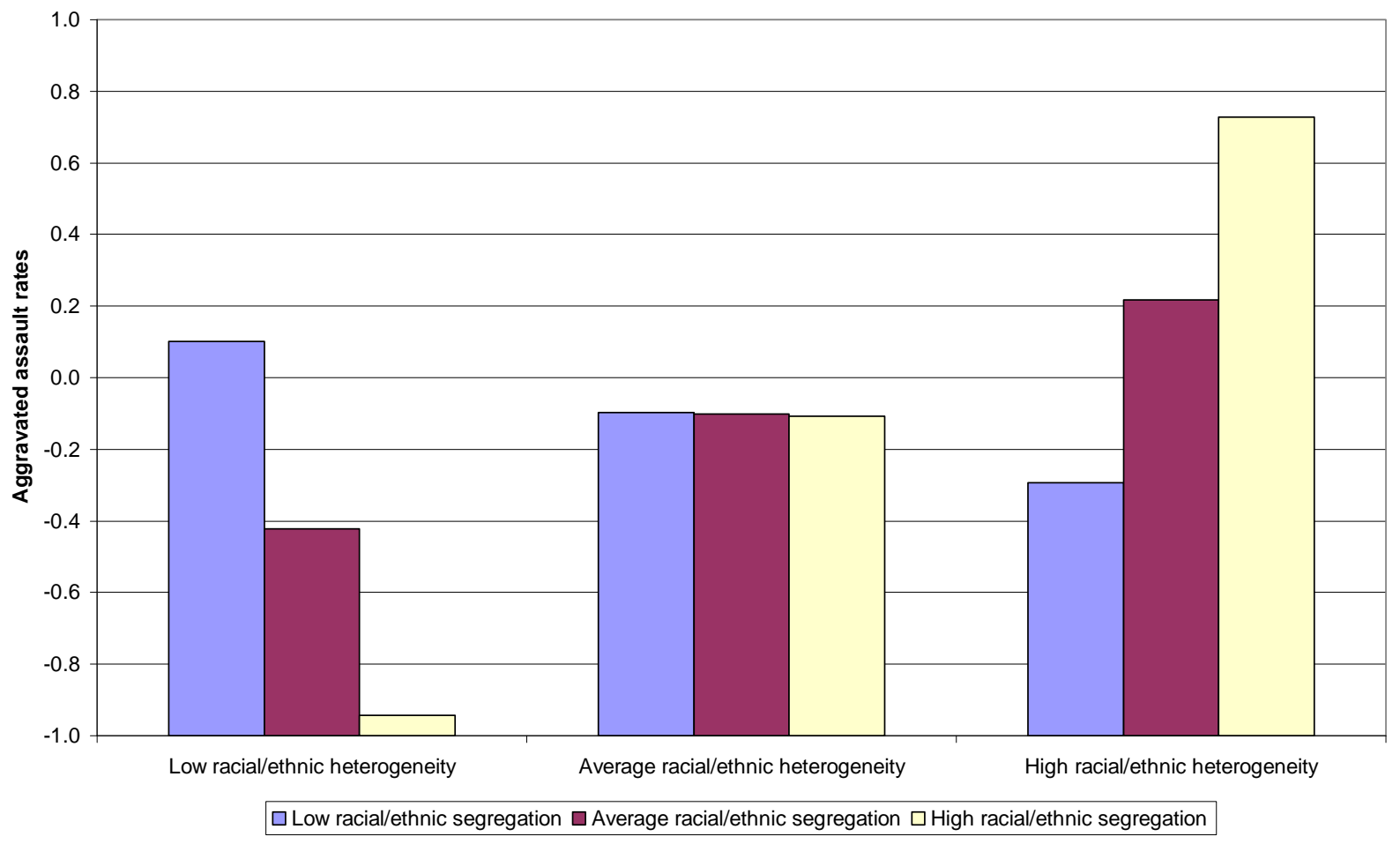


This document is a research report submitted to the U.S. Department of Justice. This report has not been published by the Department. Opinions or points of view expressed are those of the author(s) and do not necessarily reflect the official position or policies of the U.S. Department of Justice.

Figure 10

Figure 10. Robbery rates predicted by interaction of racial/ethnic heterogeneity and segregation

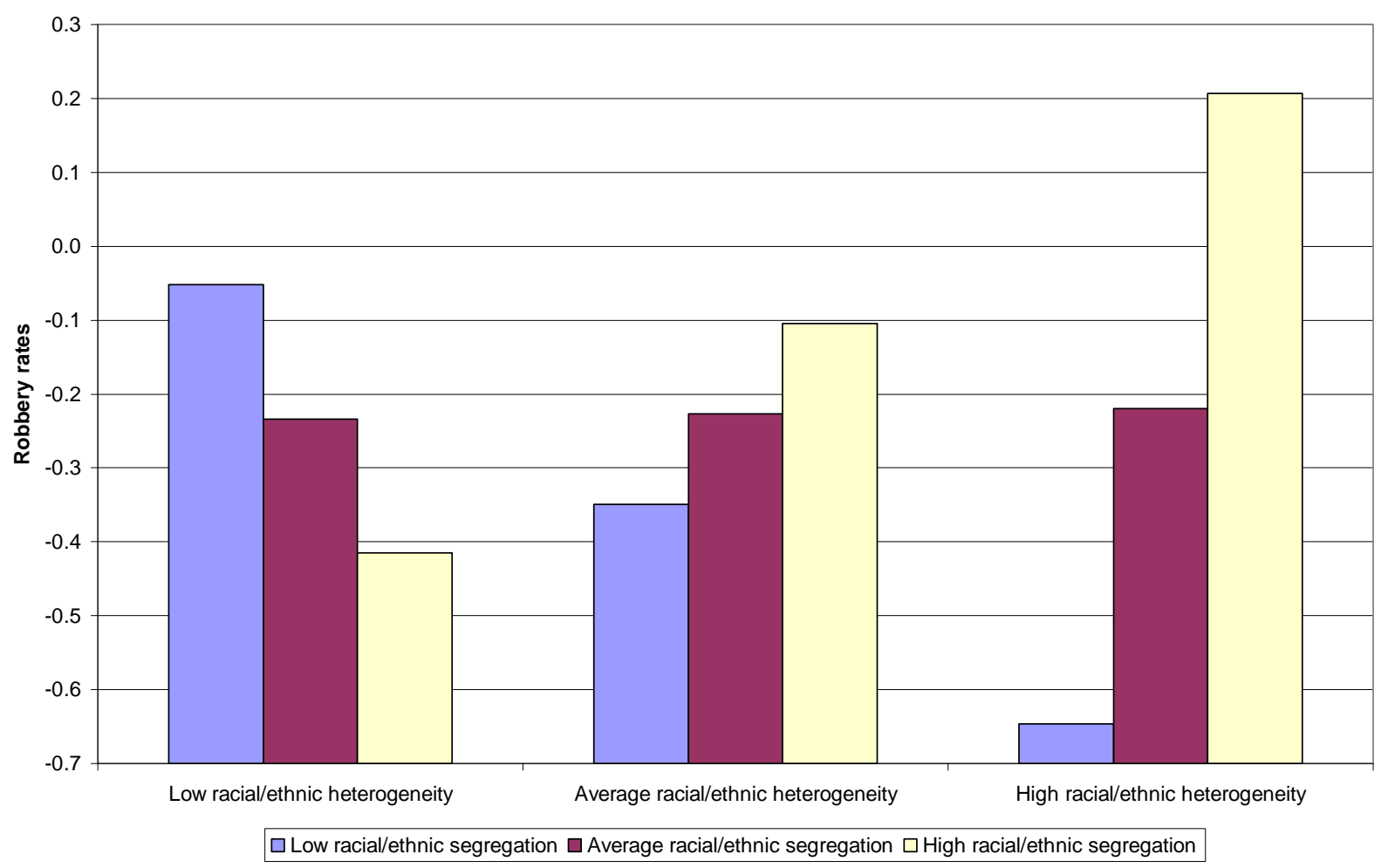


This document is a research report submitted to the U.S. Department of Justice. This report has not been published by the Department. Opinions or points of view expressed are those of the author(s) and do not necessarily reflect the official position or policies of the U.S. Department of Justice.

\section{Figure 11}

Figure 11. Burglary rates predicted by interaction of racial/ethnic heterogeneity and segregation

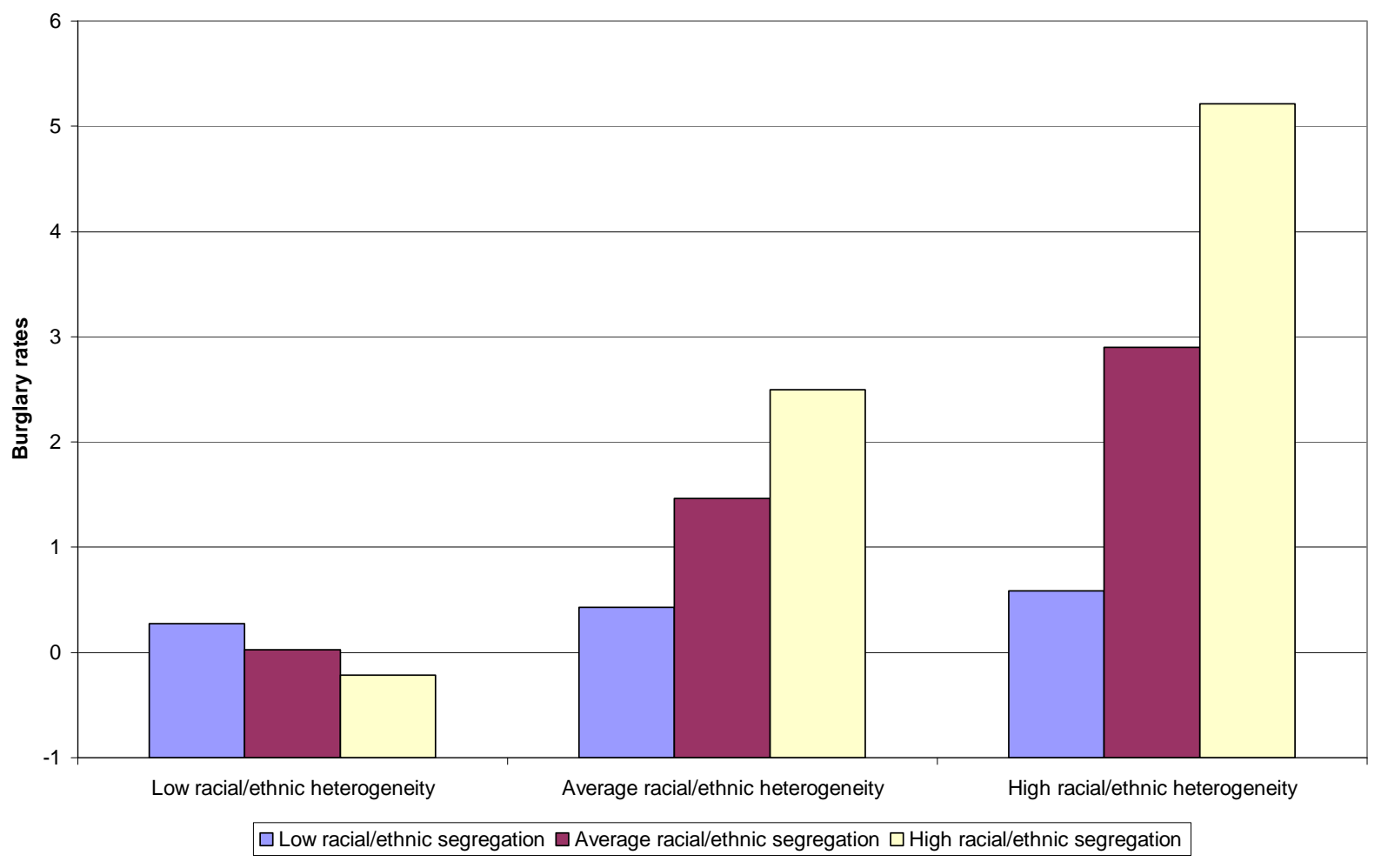


This document is a research report submitted to the U.S. Department of Justice. This report has not been published by the Department. Opinions or points of view expressed are those of the author(s) and do not necessarily reflect the official position or policies of the U.S. Department of Justice.

\section{Figure 12}

Figure 12. Motor vehicle theft rates predicted by interaction of racial/ethnic heterogeneity and segregation

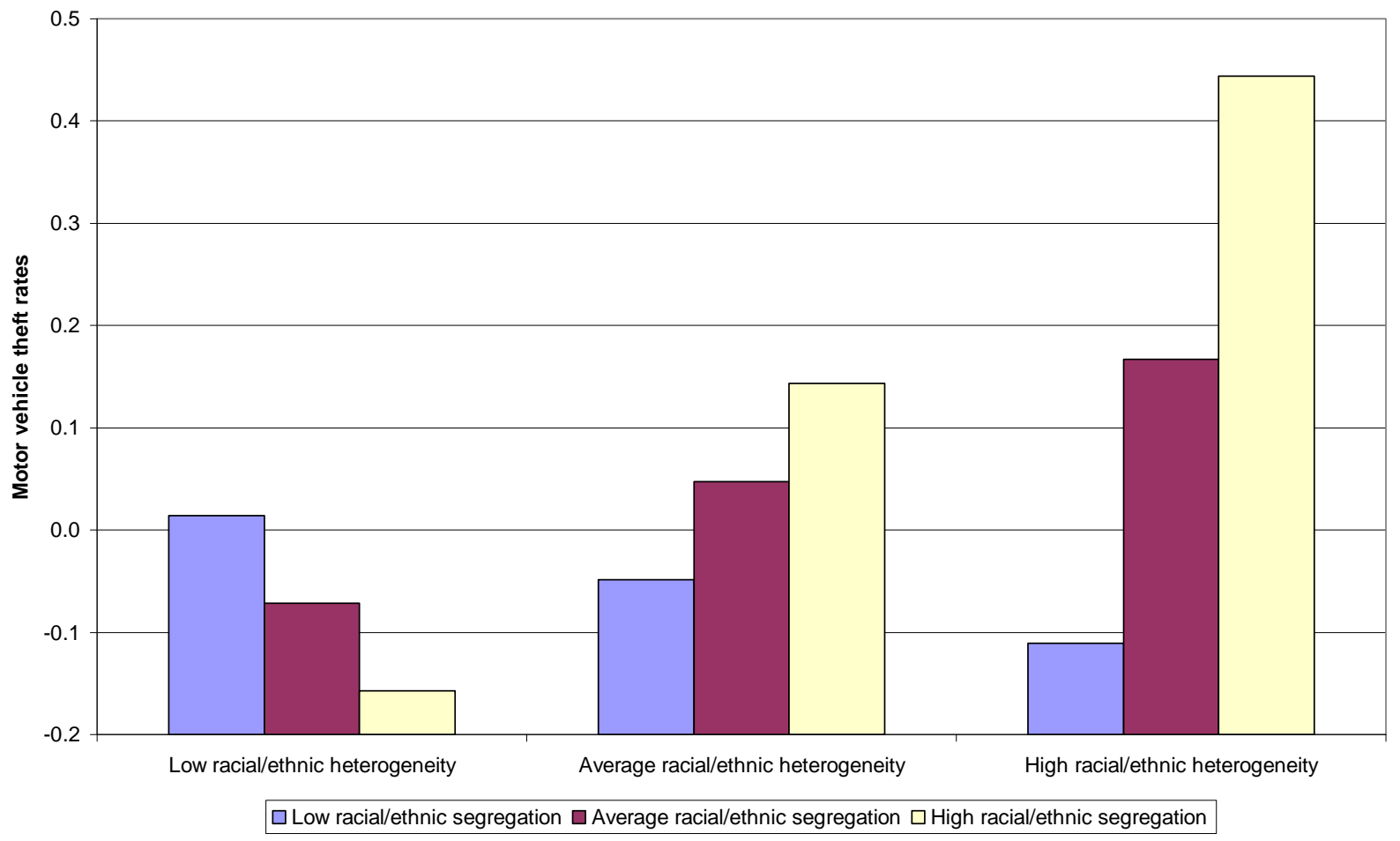


This document is a research report submitted to the U.S. Department of Justice. This report has not been published by the Department. Opinions or points of view expressed are those of the author(s) and do not necessarily reflect the official position or policies of the U.S. Department of Justice.

\section{Figure 13}

Figure 13. Change in aggravated assault rates predicted by interaction of racial/ethnic churning and change in segregation

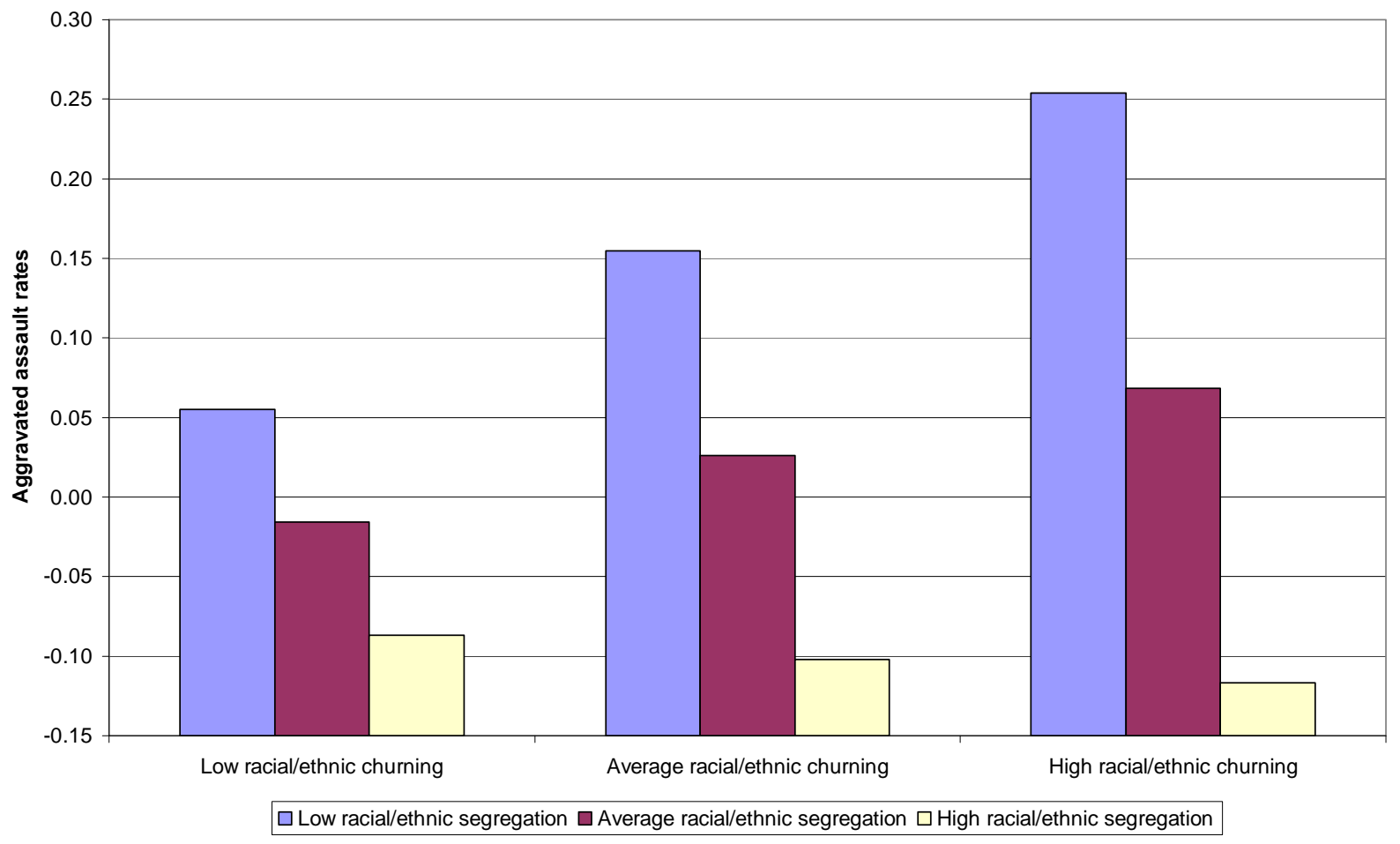


This document is a research report submitted to the U.S. Department of Justice. This report has not been published by the Department. Opinions or points of view expressed are those of the author(s) and do not necessarily reflect the official position or policies of the U.S. Department of Justice.

Figure 14

Figure 14. Change in motor vehicle theft rates predicted by interaction of racial/ethnic churning and change in segregation

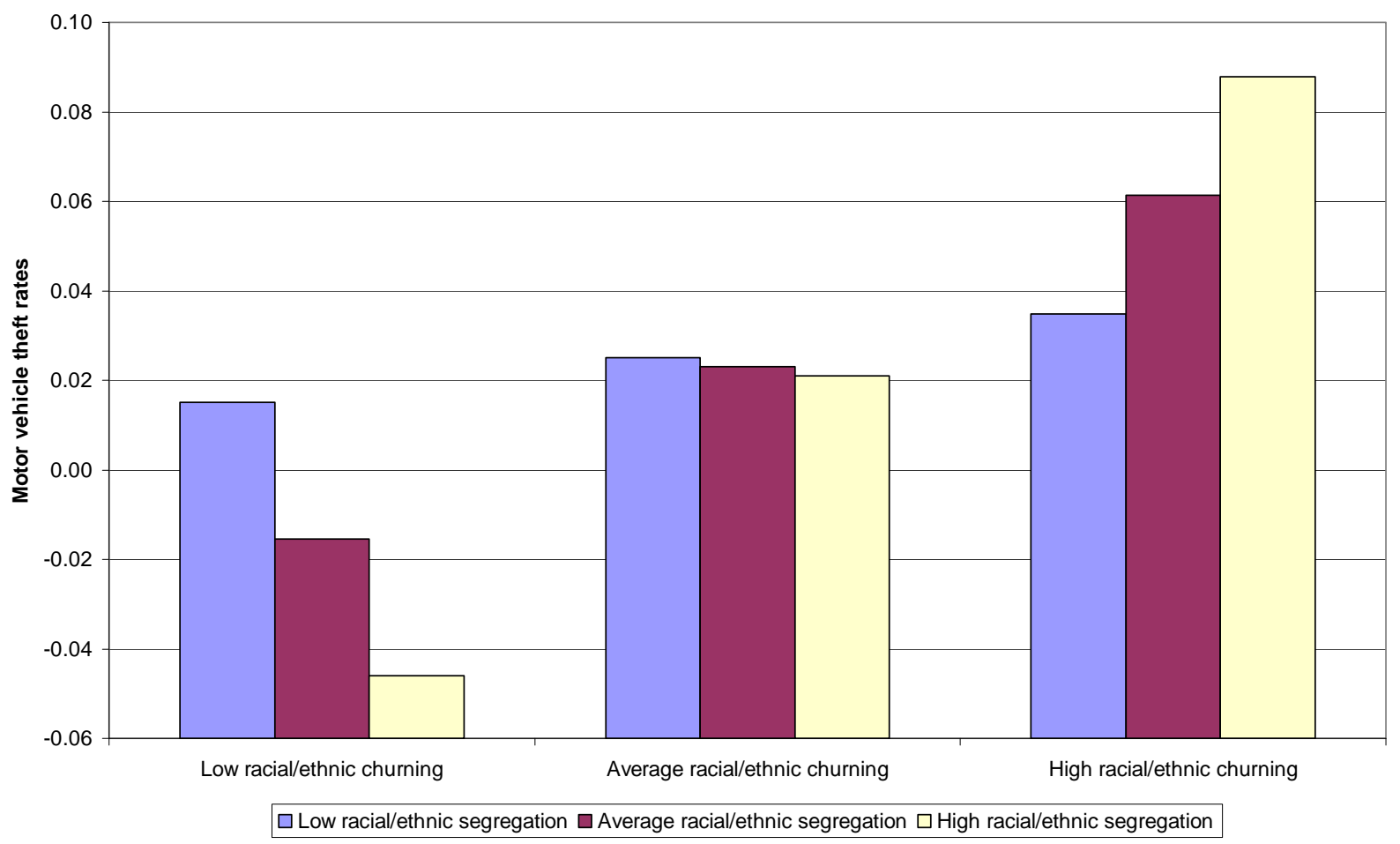

